\title{
LAS SEMICONSONANTES Y SEMIVOCALES EN LOS DIPTONGOS DEL ESPAÑOL: PROPUESTA DE ANÁLISIS FONOLÓGICO
}

\author{
Annette Calvo Shadid
}

\begin{abstract}
RESUMEN
El presente estudio toca algunos puntos importantes sobre la fonética y la fonología de los segmentos considerados semiconsonantes en español, puesto que su estatus fonológico sigue sin estar claro. Plantea las siguientes cuestiones respecto de las semiconsonantes y semivocales de los diptongos en español: Si, de hecho, resulta relevante la división entre semivocales y semiconsonantes en los diptongos descendente y ascendente en español; si las deslizadas [j] y [w] de los diptongos, las cuales tradicionalmente se han asignado a $/ \mathbf{i} /$ y $/ \mathbf{u} /$, son asignables a unos fonemas $/ \mathbf{j} /$ y $/ \mathbf{w} /$, y si las secuencias de deslizada más vocal forman núcleos silábicos complejos.

Palabras clave: español, fonología, diptongos, semiconsonantes, semivocales.
\end{abstract}

\begin{abstract}
This article studies some important points about glides in Spanish, since their phonological status doesn't seem to be clear. It raises the following issues: if, in fact, it's relevant a division between semivowels and semiconsonants in Spanish diphtongs, if glides can be assigned to /i/ and /u/ phonemes or to $/ \mathbf{j} /$ and $/ \mathbf{w} /$ phonemes, and if sequences of glide plus vowel form complex syllabic nucleus.

Key words: Spanish, phonology, diphtongs, semiconsonants, semivowels.
\end{abstract}

\section{Introducción}

A partir de una pregunta que lanza Mosterín (1981: 98): ¿Hasta qué punto los fonemas de una lengua están dados en la realidad de esa lengua y con independencia de la actividad ordenadora y clasificadora del fonólogo, y hasta qué punto son el resultado de esa actividad, la creación de fonólogo? se analizan aquí algunos segmentos fónicos del español, tales como las semiconsonantes y semivocales en los diptongos, las cuales han creado discusión y discrepancia entre los fonólogos de la lengua española.

Dra. Annette Calvo Shadid. Departamento de Lingüística. Universidad de Costa Rica. Correo electrónico: acalsha@yahoo.com.mx

Recepción: 22- 5- 2009

Aceptación: 16- 6- 2009 


\subsection{Justificación}

El presente tema toca puntos importantes sobre la fonética y la fonología de los segmentos considerados semiconsonantes y semivocales en español, puesto que su estatus fonológico sigue sin estar claro, lo cual ocasiona una dificultad para explicar, tanto a nivel de modelo teórico como pedagógico, los fenómenos de consonantización de dichos segmentos en posición inicial de palabra, por ejemplo, o las diferencias entre ellos en posiciones de diptongos crecientes y decrecientes.

\subsection{Objetivos}

\subsubsection{Objetivo general}

Presentar un panorama teórico sobre las semivocales y semiconsonantes en español.

\subsubsection{Objetivos específicos}

1. Presentar un estado de la cuestión sobre el estatus fonológico de las semivocales y semiconsonantes en español, y su posición dentro de la sílaba.

2. Plantear una propuesta teórica sobre el estatus fonológico de las semivocales y semiconsonantes en el español de Costa Rica.

\subsection{Definiciones}

Los términos semivocal y semiconsonante se refieren a sonidos que no conforman característicamente ni una vocal ni una consonante. Por ejemplo, las vocales $i$ o $u$ cuando forman diptongo con cualquier vocal que forme núcleo de sílaba.

También, a estos sonidos se les conoce como deslizados; contempla sonidos que no son ni vocálicos ni consonánticos, pues su articulación constituye un pasaje gradual de un sonido a otro. Por tanto, según algunos, nunca forman núcleo silábico y, según otros, forman un núcleo complejo junto con la vocal plena. También se conocen como elementos de transición.

\section{Las vocales en español}

Es claro que el español tiene cinco fonemas vocálicos ${ }^{1}$ los cuales, a su vez, muestran contraste entre sí en posición acentuada. Este sistema se caracteriza por ser bastante estable ${ }^{2}$, y se distingue por tres grados de apertura y tres posiciones articulatorias de la lengua, como se muestra en el siguiente cuadro.

Cuadro 1. Fonemas vocálicos del español

\begin{tabular}{cccc} 
& Anterior & Central & Posterior \\
\hline Cerrada & / i $~$ & & $/ \mathrm{u} /$ \\
Media & $/ \mathrm{e} /$ & & $/ \mathrm{o} /$ \\
Abierta & & $/ \mathrm{a} /$ & \\
\hline
\end{tabular}

Fuente: Propia 
En posición inacentuada, el sistema se restringe, dado que las posibilidades combinatorias disminuyen en la sílaba final no acentuada: se presentan, principalmente, las vocales /a, e, o/, pues /i, u/ aparecen con menos frecuencia ${ }^{3}$.

Otros casos de reducción vocálica ocurren también en el proceso de debilitamiento vocálico denominado en español vocales caedizas, fenómeno que se da principalmente en México y en diversas zonas de los Andes, en el cual es posible que todas las vocales se reduzcan en posición inacentuada y antes o después de consonante sorda.

Los resultados de Delforge (2008) para El Cuzco, Perú, han aportado nuevos datos al tópico de las vocales caedizas en español y sus contextos lingüísticos. Estos presentan, en orden descendente, el índice de reducción vocálica inacentuada (unstressed vowel reductionUVR) por su posición en la palabra.

Cuadro 2. Porcentajes de desonorización por posición de palabra

\begin{tabular}{ccc}
\hline \multicolumn{3}{c}{ Devoicing rate } \\
\hline Vowel & Word-Medial & Word-Final \\
\hline /u/ & $22 \%$ & $19 \%$ \\
$\mathrm{li} /$ & $13 \%$ & $20 \%$ \\
$\mathrm{le} /$ & $13 \%$ & $20 \%$ \\
$\mathrm{lo} /$ & $1.5 \%$ & $18 \%$ \\
$\mathrm{la} /$ & $1 \%$ & $15 \%$ \\
\hline
\end{tabular}

Table 4. Devoicing rates by Word position

Fuente: Delforge (2008:114)

Esto indica que las vocales más susceptibles de debilitamiento en posición inacentuada son /u/, /i/ y /e/. Las vocales /o/ y /a/ presentan poca desonorización o debilitamiento. Delforge (2008:119) presenta varios argumentos para explicar tal debilitamiento: por ejemplo, la contribución de la posición final de sílaba y la de la posición inmediatamente postónica. Argumenta que el ensordecimiento sandhi también actúa pero afecta solo a las vocales altas y a /e/, y que la sílaba inacentuada trabada por /s/ en posición inmediatamente postónica y final favorece altamente la desonorización.

Por otra parte, las vocales /a/, /e/, /o/, no presentan mayores dificultades de interpretación fonológica, pues casi siempre se presentan como vocales plenas en posición nuclear de sílaba ${ }^{4}$. Sin embargo, la situación es más compleja cuando se trata de las vocales /i / y /u/ en posiciones en que no constituyen vocales plenas, como en los diptongos.

En este sentido, diversos teóricos y profesores de español como lengua materna y como segunda lengua, han tratado de explicar este problema desde varios enfoques teóricos, como se mostrará en el siguiente apartado.

\section{Propuestas teóricas sobre las semivocales y las semiconsonantes del español}

Una de las primeras propuestas sobre el estudio de la fonética del español es la de Navarro Tomás (1918/61). Denomina semivocal a la [ i ] de los diptongos ai, ei, oi. Respecto de sus características articulatorias, señala (1918/61:48) que esta [ $\underset{n}{i}$ ] no es un sonido prolongable y uniforme como las vocales $i, i$, sino que, como verdadera semivocal, se produce con articulación momentánea, con tendencia a cerrar progresivamente su abertura palatal. 
Respecto de la semiconsonante [j] y sus características articulatorias, señala (1918/61:49) que la disposición general de los órganos es intermedia entre la articulación de la vocal i y la de la consonante y; la fricación palatal es, de ordinario, muy poco perceptible; la duración del sonido es brevísima.

Al mencionar los diptongos en posición inicial de sílaba, señala que la /i/ se consonantiza (1918/61:49-50) en este mismo contexto, y que en la pronunciación esmerada por influencia de la escritura se articula como semiconsonante. Para Navarro Tomás hay, en la mayoría de los casos, una consonante en los diptongos que se encuentran en posición inicial de sílaba:

(...) la i inicial del diptongo se pronuncia generalmente como consonante, no haciéndose, por consiguiente, diferencia alguna, en cuanto al sonido inicial, entre hierba y yegua, hierro y yeso, hiena y yema, etc. Bajo la influencia de la escritura suele hacerse distinción, en pronunciación esmerada, entre dichas formas diciendo hierba, hierro, hiena, con semiconsonante $\mathrm{j}$, y yeso, yegua, yema, con consonante y; pero lo corriente es, (...), pronunciar una verdadera consonante palatal en unos y en otros casos.

Por otro lado, respecto de la articulación de [u్n] semivocal, señala (1918/61:62):

\begin{abstract}
Su articulación consiste en el breve movimiento que realizan los órganos para pasar desde la posición de una vocal precedente a la de una u, que antes de desarrollarse bajo una forma determinada es interrumpida por la articulación o pausa siguientes. Los órganos, al fin de este movimiento de aproximación, forman una doble estrechez, linguovelar y bilabial, que aun tendiendo al tipo fricativo, mantiene claramente su timbre vocálico de u más o menos cerrada.
\end{abstract}

Respecto de la articulación de la semiconsonante [w] la equipara, como la de [j], con un cierre articulatorio semejante al de una fricativa (1918/61: 63):

\begin{abstract}
Al contrario de lo que sucede en la u semivocal, la articulación de la w consiste precisamente en el movimiento que realizan los órganos al pasar de una manera rápida desde una posición labiovelar relativamente cerrada a la posición de cualquier otra vocal siguiente; la articulación de la u empieza más abierta que acaba; la de la w, por el contrario, como la de la j, empieza casi tan cerrada como una consonante fricativa y se abre gradualmente sin detenerse en ningún punto determinado hasta ser interrumpida por la vocal siguiente.
\end{abstract}

Sobre la consonantización de [w] especialmente en los diptongos iniciales, el autor cita que en el habla familiar aparece como una fricativa velar labializada, o como una bilabial velarizada y cómo esta llega a convertirse en oclusiva en lo que llama habla vulgar (1918/61:64) ${ }^{5}$ :

\begin{abstract}
A veces la w aparece entre vocales, ahuecar, o en posición inicial absoluta, hueso, y en estos casos el punto de partida de su articulación toma aún más carácter de consonante que cuando va dentro de sílaba entre consonante y voca1; los labios se aproximan más entre sí y la lengua se acerca más al velo del paladar, llegando especialmente en la conversación familiar a desarrollarse delante de dicha w una verdadera consonante que, según predomine la estrechez de los órganos en uno u otro punto, aparece como una y labializada o, menos frecuentemente, como una $\beta$ velarizada: ahuecar-awekáı, ayweká o aßwekád; hueso-wéso, \wéso o ßweso (el habla vulgar lleva corrientemente este elemento hasta el grado oclusivo cuando la w es inicial absoluta o va precedida de nasal: huevo - gweßo o bweßo, un hueso - ún gweso o úm bwéso).
\end{abstract}

Así, el autor corrobora en su Pronunciación española, que los segmentos [j] y [w] bien pueden convertirse en consonantes plenas con oclusión y, para ambos segmentos, señala que esto se da en diptongos en posición inicial de palabra o después de nasal. El autor propone que las consonantizaciones en posición inicial aparecen en lo que él llama habla vulgar, familiar y en los contextos de habla no muy cuidadosa; en pronunciación esmerada, 
influenciada por la escritura, las consonantizaciones son mucho menores en los diptongos crecientes, en los cuales se articulan, principalmente, las semiconsonantes.

Por otra parte Navarro Tomás (1946/66:13), en sus Estudios de Fonología Española, sostiene que el sistema fonológico del español consta de cuarenta y dos fonemas; cinco vocales, diecinueve consonantes, seis diptongos decrecientes, ocho crecientes y cuatro triptongos. Señala que los diptongos son fonemas o unidades que llevan a cabo un contraste total entre ellos y las vocales, no por su distribución, sino por las oposiciones que establecen entre palabras:

\footnotetext{
Fonológicamente desempeñan igual función que los fonemas simples. Lo que hace diferentes a celo y cielo o a vente y veinte no es la presencia o ausencia de la i sino el contraste total entre vocales y diptongos. No es tampoco la impresión de una parte del diptongo ue sino su efecto de conjunto lo que hace que una palabra como tuerca, por ejemplo, se diferencie de terca o turca.

Las semivocales y semiconsonantes no se manifiestan en los vocablos con la individualidad definida que da a los demás sonidos el poder aparecer en posición aislada intervocálica o interconsonántica. El sentimiento de la unidad del diptongo se ratifica con la correspondencia de palabras como puerta-portero, tiene-tenía. La división del diptongo en fonemas independientes desfiguraría en la mayor parte de los casos la representación fonológica de la palabra.
}

Asimismo, el autor plantea una lista de los fonemas del español y sus índices de frecuencia, con el fin de tomar en cuenta el volumen que cada fonema representa en el conjunto material sonoro que la lengua utiliza. Y agrega: (1946/66:15) La escala de frecuencia de los fonemas es base indispensable para conocer la composición de cada lengua, para comparar unas lenguas con otras y para señalar el orden conveniente en la enseñanza de la pronunciación.

\section{Esquema-resumen 1. Síntesis de TNT (1918/61 y 1946/66)}

1. Respecto de las características articulatorias de las semivocales y las semiconsonantes, de las primeras señala que su producción se realiza con articulación momentánea de las segundas indica que la duración del sonido es brevísima.

2. Al mencionar los diptongos en posición inicial de sílaba, señala que la /i/ y la /u/ se consonantizan en este contexto, y que en la pronunciación esmerada por influencia de la escritura se articulan como semiconsonantes.
3. Para Navarro Tomás hay, en la mayoría de los casos, una consonante en los diptongos que se encuentran en posición inicial de sílaba.

4. El autor considera, a partir del análisis que lleva a cabo, que los diptongos conforman fonemas, y que las semivocales y semiconsonantes no se manifiestan en los vocablos con individualidad definida.

Bowen y Stockwell (1955) postulan que $[\mathrm{j}]^{6} \mathrm{y}[\mathrm{w}]$, que tradicionalmente se han asignado a /i/ y /u/ deberían asignarse a los fonemas /j/ y /w/, respectivamente. El alófono de /j/ sería tenso, sonoro, prepalatal, fricativo de /cabajo/ y de /jo/.

Se asignarían los alófonos en posición inicial con el siguiente par mínimo, en contraste con /i/:

(a) ya visto /jábísto/

(b) y ha visto /iábísto/

Un casi par mínimo para /w/ y /u/, en contraste con /u/ es:

(c) huaca /wáka/

(d) u oca /uóka/ 
Esta misma interpretación es posible para la posición intervocálica; sin contraste $\operatorname{con} / \mathrm{i} / / \mathrm{u} /$ :

(e) allá /ajá/
(f) agua /áwa/

Los siguientes ejemplos muestran que $[\mathrm{j}]$ y [w] en los siguientes contextos se asignarían también a /j / y /w/, respectivamente, En (j), las semivocales son asignadas también a /j/ y /w/ por analogía con los ejemplos (a) a (d) anteriores; en (k) son asignadas a los ejemplos (e) y (f). Así, los ejemplos (l), (m), (n) también estarían asignados a /j/ y /w/ sobre la base de una analogía fonética, regularidad de modelo y simplicidad morfofonémica.
(j) ${ }^{7} \mathrm{SV}$ :
yo
huerta
(k) VSV:
allá
(l) CSV:
bien
agua
(m) VSC: baile
bueno
(n) VS:
hoy
auto
Grau (patronímico)

Por otro lado, en virtud del modelo secuencial en español, resumen todos los grupos iniciales de sílaba en tres formas: $\mathrm{CR}^{8}, \mathrm{CS}$ y $\mathrm{CRS}$. Argumentan que este es un modelo secuencial más regular. Es decir, habría una clase de fonemas $/ \mathbf{j}, \mathbf{w}, \mathbf{r}, \mathbf{l} /$ que siempre aparecen en segundo lugar en las secuencias iniciales. Además, incluyen en el sistema vocálico del español tanto núcleos simples (vocales simples) como núcleos complejos (combinación de vocal $+/ \mathbf{j} /$ o $/ \mathbf{w} /$ ). Así, S formaría parte de los núcleos complejos solo en las combinaciones señaladas a continuación.

\begin{tabular}{ccc}
\hline Núcleos simples & Núcleos complejos \\
\hline$i$ & --- & iw \\
$e$ & ey & ew \\
$a$ & ay & aw \\
$o$ & oy & -- \\
$u$ & uy & -- \\
\hline
\end{tabular}

Además, su análisis pretende eliminar la alternancia morfofonológica en algunos sufijos de tercera persona como los de com-ió, com-ieron y le-yó, le-yeron, proponiendo el mismo fonema /j/: /comjó/, /comjéron/ y /lejó/, /lejéron/. Es decir, ambas formas tienen los mismos sufijos /-jó/, /-jeron/. Argumentan una ganancia en simplicidad morfofonológica.

Respecto del grupo consonántico establecido en (m), a saber, VSC, lo comparan con las formas 'oigo' /óigo / y 'prohibo' /proíbo/, que en Costa Rica sería /prójbo/ para muchas personas. Los núcleos principales al trasladar el acento en oigamos /ojgámos/ y en /projbír/ (en el español de Costa Rica no es /proibir/, sino /projbir/, según señalan los autores) se resuelven de la siguiente forma: 1. colocando un tercer nivel de acento en /prǒibír/ pero no en /ǒigámos/, o 2. suponiendo una transición abierta en /pro + ibir/. 
Por otro lado, explicarían las oposiciones como hay una frente a ayuna con una transición abierta después de /y/ o /w/ final de palabra + vocal:

Hay una: /ay + unal

Ayuna: lajunal

Los autores concluyen contundentemente: La solución que ofrecemos es la única que puede abarcar todos los hechos y creemos que ofrece cierta conveniencia y consistencia, deseables en una descripción estructural.

Esquema-resumen 2. Síntesis de Bowen y Stockwell (1955)

\begin{tabular}{|c|c|}
\hline $\begin{array}{l}\text { 1. Postulan que }[\mathrm{j}] \text { y }[\mathrm{w}] \text {, que tradicionalmente } \\
\text { se han asignado a } / \mathbf{i} / \mathrm{y} / \mathbf{u} / \text {, deberían asignarse } \\
\text { a los fonemas } / \mathbf{j} / \mathrm{y} / \mathbf{w} / \text {, respectivamente, en } \\
\text { posición inicial de palabra, ya ha visto, /j/ } \\
\text { entre vocales agua /w/. } \\
\text { 2. Sostienen sus argumentos sobre la base de una } \\
\text { analogía fonética, regularidad de modelo y } \\
\text { simplicidad morfofonológica. } \\
\text { 3. Habría también una clase de fonemas /j, w, } \\
\text { r, l/ que siempre aparecen en segundo lugar } \\
\text { en las secuencias iniciales. }\end{array}$ & $\begin{array}{l}\text { 4. Incluyen en el sistema vocálico del español } \\
\text { tanto núcleos simples (vocales simples) como } \\
\text { núcleos complejos (combinación de vocal + } \\
\text { /j/ o/w/). } \\
\text { 5. Pretenden eliminar la alternancia } \\
\text { morfofonológica en algunos sufijos de tercera } \\
\text { persona como los de com-ió, com-ieron y le- } \\
\text { jó, le-jeron proponiendo el mismo fonema /j/: } \\
\text { /comjó/, /comjéron/ y /lejó/, /lejéron/. Ambas } \\
\text { formas tienen los mismos sufijos /-jó/, /-jeron/. } \\
\text { 6. Explican las oposiciones como hay una frente } \\
\text { a ayuna con una transición abierta después de } \\
\text { /j/ o /w/ final de palabra + vocal. }\end{array}$ \\
\hline
\end{tabular}

Saporta (1956) en una réplica, intenta demostrar que la propuesta de Bowen y Stockwell es insostenible. Revela otros casi pares mínimos para señalar los contrastes entre $/ \mathbf{i} / \mathrm{y} / \mathbf{j} / 9$ :

\begin{tabular}{|c|c|c|c|c|}
\hline (1) & $\begin{array}{l}\text { /abjékto/ } \\
\text { /abierto/ }\end{array}$ & $\begin{array}{l}\text { [a } \beta d z e k t o] \\
\text { [a } \beta \text { jerto] }\end{array}$ & $\begin{array}{l}\text { abyecto } \\
\text { abierto }\end{array}$ & $\begin{array}{l}\text { /...bjé.../ } \\
\text { /...bié.../ }\end{array}$ \\
\hline (2) & $\begin{array}{l}\text { /injeksión/ } \\
\text { /niébe/ }\end{array}$ & $\begin{array}{l}\text { [indzeksjon] } \\
\text { [njéße] }\end{array}$ & $\begin{array}{l}\text { inyección } \\
\text { nieve }\end{array}$ & $\begin{array}{l}\text { /...nje.../ } \\
\text { /...nié.../ }\end{array}$ \\
\hline (3) & $\begin{array}{l}\text { /desjélo/ } \\
\text { /desiérto/ }\end{array}$ & $\begin{array}{l}\text { [dezdzélo] } \\
\text { [desjérto] }\end{array}$ & $\begin{array}{l}\text { deshielo } \\
\text { desierto }\end{array}$ & $\begin{array}{l}\text { /...sjé.../ } \\
\text { /...sié.../ }\end{array}$ \\
\hline
\end{tabular}

Así, [dz] ${ }^{10}$ y [j] contrastan en el marco C...V; se asigna la primera a /j/ y la segunda a /i/. La distribución de /j/ y de /i/ se esquematiza como sigue:

\begin{tabular}{llc}
\hline & $/ \mathbf{j} /$ & / $\mathbf{i} /$ \\
\hline$\# \ldots \mathrm{V}$ & yo & y ha visto \\
$\# \ldots \mathrm{C}$ & -- & hijo \\
$\# \ldots \#$ & deshielo & desierto \\
\hline
\end{tabular}
continúa... 
...continuación

\begin{tabular}{llc}
\hline & $/ \mathbf{j} /$ & $/ \mathbf{i} /$ \\
\hline $\mathrm{C} \ldots \mathrm{C}$ & -- & cine \\
$\mathrm{C} \ldots \#$ & -- & comí \\
$\mathrm{V} . . . \mathrm{V}$ & leyes & leía \\
$\mathrm{V} \ldots \mathrm{C}$ & -- & baile \\
$\mathrm{V} . . . \#$ & - & ley
\end{tabular}

De acuerdo con el esquema anterior, /j/ e /i/ contrastan delante de vocales, pero solo /i/ aparece ante consonantes y precediendo a una pausa.

Critica el criterio de la simetría del modelo de Bowen y Stockwell, y señala: No está claro cómo la simetría del modelo pueda ser a la vez un criterio y un resultado en el análisis lingüístico, sin que exista una circularidad.

Respecto del deslizamiento prenuclear en bueno como /u/ y no como /w/ señala, para los contextos C...V:

\begin{tabular}{|c|c|c|c|}
\hline /deswesár/ & [dezw̌esar] & deshuesar & /...swe.../ \\
\hline /desuéyo/ & [deswéyo] & desuello & /...sué.../ \\
\hline /suéko/ & [swéko] & sueco & /...sué.../ \\
\hline /sónwéßos/ & [soךweßos] & son huevos & /...nwé.../ \\
\hline /sónnué $\beta$ os/ & [sonwé $\beta$ os] & son nuevos & /...nué.../ \\
\hline
\end{tabular}

Nuevamente, los sonidos con fricción son asignados a /w/, y aquellos que no la tienen, a $/ \mathbf{u} /$.

Juzga, además, como desafortunada, la posición de B \& S respecto de la simplicidad morfofonológica, pues llega más bien a complicarla en otras formas. En los casos de comió y leyó, en que los autores proponen /-jó/ para ambos casos, el análisis se complicaría teniendo que contrastar la raíz con dos alomorfos: uno con /i/ en /raís/ 'raíz' y otro con /j/ en /rajsílla/ 'raicilla'.

Respecto de los grupos consonánticos, Saporta también se encuentra en desacuerdo con los autores anteriores. Su crítica es que B \& S no regularizan en forma apreciable su modelo. Señala: Las fórmulas para los grupos iniciales $C R, C S, C R S$ quedan reducidas a $C R$ con la desaparición de $S$.

Saporta considera el contraste entre los núcleos oigamos y prohibir. La diferencia podría superarse indicando todos los acentos y no solo los primarios: oigamos /ǒigámǒs/ y prohibir /prǒǐbír/. Señala: La transcripción fonológica /oi/ sin ningún acento indicado es por cierto ambigua. Así, propone: 


\begin{tabular}{llc}
\hline (a) & /ǒ i/ & oigamos \\
(b) & /ǒ ̌̌/ & prohibir \\
(c) & /ǒ í/ & oí \\
(d) & /ó i/ & hoy $\mathrm{i} /$ \\
(e) & /ó í/ & cantó y bailó \\
(f) & cantó himnos \\
\hline
\end{tabular}

Por último, se manifiesta de acuerdo con los núcleos complejos de B \& S. Coloca /ow/ en la lista de núcleos complejos, que no había sido contemplado por los autores.

\section{Esquema-resumen 3. Síntesis Saporta (1956)}

1. Revela nuevos casi pares mínimos para señalar los contrastes entre /i/ y /j/, oponiéndose a la propuesta de $\mathrm{B} \& \mathrm{~S}: / \mathbf{j} /$ e /i/ contrastan delante de vocales, pero solo /i/ aparece ante consonantes $\mathrm{y}$ precediendo a una pausa.

2. Respecto del deslizamiento prenuclear en bueno como/u/ y no como /w/ señala, para los contextos C...V: los sonidos con fricción son asignados a /w/, y aquellos que no la tienen, a /u/.

3. Está en desacuerdo con B\&S también, en las interpretaciones fonológicas de comió y leyó, en que los autores proponen /-jó/ para ambos casos; el análisis se complicaría teniendo que contrastar la raíz con dos alomorfos: uno con /i/ en /raís/ 'raíz’y otro con /j/ en /rajsílla/ 'raicilla'. Respecto de los grupos consonánticos, también se encuentra en desacuerdo con $\mathrm{B} \& \mathrm{~S}$. Su crítica es que no regularizan en forma apreciable su modelo: Las fórmulas para los grupos iniciales $C R, C S, C R S$ quedan reducidas a CR con la desaparición de $S$.

4. Está de acuerdo con los núcleos complejos de B \& S y agrega /ow/ en la lista de núcleos complejos.

El estudio de Alarcos Llorach (1961/83:151) plantea dos problemas de tipo fonológico:

$1 .^{\circ}$, ¿estos diptongos son monofonemáticos, o bien combinaciones de dos fonemas diferentes?, y $2 .^{\circ}$, en el último supuesto, el elemento más cerrado del diptongo, el llamado semiconsonante o semivocal, ¿es un fonema independiente o bien mera variante de las vocales /i, u/? En otras palabras: ies cada diptongo realización fonética de un solo fonema?, ¿tienen valor distintivo las semivocales y las semiconsonantes, o se identifican como variantes de otros fonemas?

A partir de estas dos preguntas desarrolla el siguiente despliegue teórico. Respecto de la primera pregunta Alarcos, basado en las reglas de Trubetzkoy (1939:50-57) para determinar la naturaleza monofonemática de dos sonidos sucesivos ${ }^{11}$, llega a la conclusión de que los diptongos carecen de valor monofonemático y son combinaciones de los cinco fonemas vocálicos con otro elemento.

Luego, desarrolla el tema de la segunda interrogante respecto de si los elementos [j], [i ], [w] y [u] son fonemas independientes o bien variantes de otros fonemas. Como estos no aparecen nunca en un mismo contexto, (regla III de Trubetzkoy) considera que tanto [j], [i] e [i], son variantes combinatorias de /i/, como [w ], [un] y [u], lo son de /u/. Cita el autor (1961/83:153): 
[ j ] y [ w ] pertenecen a la clase de variantes prenucleares de la sílaba, [ i ] y [ u ] a la clase de variantes postnucleares; mientras que [ i ] y [ u ] son variantes que funcionan como núcleo silábico. Tampoco cumplen estos sonidos la regla IV de Trubetzkoy: nunca aparecen en combinación los unos con los otros; esto es, no existen los grupos *[ ji ], *[ ii ], *[ wu ], *[ uun ], los cuales darían independencia fonológica a las variantes marginales con respecto a los fonemas $/ \mathbf{i} /, / \mathbf{u} /$.

Posteriormente, se refiere a la relación que hay entre $[j]$ y [i] y la consonante $[y]^{12}$, y cómo algunos piensan que los tres son variantes del fonema consonántico $/ \mathbf{y} /^{13}$. Alarcos (1950/83:154) rechaza esta propuesta, por una razón funcional, más que articulatoria:

Entre las variantes más cerradas del fonema /y/ (esto es, [dz $\left.{ }^{14}\right]$ ) y las más abiertas del fonema /i/ (es decir, [i]) hay una diferencia fundamental, más de función que de naturaleza articulatoria: la diferencia entre consonante y vocal (...) vocal y consonante se excluyen totalmente del mismo contexto en el decurso: [i] puede formar por sí solo sílaba mientras que ello es imposible para [y] (...) De modo que si todas las vocales se oponen a todas las consonantes, no es por sus determinados rasgos distintivos, sino por su diferente función; por tanto, si [d] $]$ es «consonante» e [i] «vocal» y se excluyen, son necesariamente dos fonemas, cada uno perteneciente a uno de los grupos que llamamos «vocales»y «consonantes».

La cuestión que plantea Alarcos sería determinar a cuál de estos dos fonemas, /y/ consonántico e /i/ vocálico se deben adscribir las otras variantes menos cerradas y menos abiertas [y], [j], [ i ]. El criterio que toma para identificar un fonema es el valor distintivo de los sonidos, es decir, todas las variantes fónicas que correspondan a un mismo significado forzosamente han de interpretarse como realizaciones de un mismo fonema. Concluye que en todos los casos observados, [j] e [i] ] son realizaciones de /i/, y proporciona los siguientes contextos de aparición:

\footnotetext{
El signo español ortografiado y admite muchas realizaciones, condicionadas por el contexto: [i] subes y bajas, [i ] cielo y tierra, [j] apagan y encienden, [y] calla y escucha, [dz] ¿y esto qué? En todos esos casos es posible también la variante «nuclear» [i]. Si en los casos como el del primer ejemplo [i] es exclusiva, y en los demás es posible, parece natural que veamos en todos esos sonidos meras realizaciones de /i/. En significantes que comienzan o terminan con /i/, observamos en el decurso, según el contexto, cierta variabilidad entre [i] e [i] o [j]: me irrita [męi ríta]; nos irrita [nosirííta]; a mí es que me molesta [amjéske ...]; a mí no es que me moleste [amíno ...]; si eres tú [sjé ...]; si vienes tú [siß...]. Añádase la vacilación entre hiato y sinalefa en ejemplos como: está riendo [riéndo], riendo a todas horas [rjeṇdo], que permite realización idéntica [eștaßarjeṇdo] para estaba riendo y está barriendo. Indudablemente, en todos estos casos [i] e [j] son realización de /i/.
}

Respecto de la consonante /y/, llega a la conclusión de que es /y/ toda realización que sea [dz] o que en tal contexto pueda alternar con esta, y proporciona los siguientes contextos (1961/83:155):

(...), en significantes como yema, yodo, hielo, yugo, rayo, haya, etc., existe variabilidad (condicionada por el contexto y por normas regionales) entre [dz], [y] e incluso [j]: el yerno [dz]; tu yerno [y], con yodo [dz]; de yodo [y]; pon hielo [dz]; quiero hielo [y]; rayo [y] (dialectalmente también [dz] o [j] y hasta [S], [3], etc.). De todos modos, vemos totalmente excluidas de estos contextos las variantes [i] ], e [i]; por ello, aquí nos encontramos con realizaciones de /y/.

Respecto de la alternancia [ $\mathrm{i}$ ] [y] en palabras como rey ['rei ], reyes ['reyes]; ay ['ain], ayes ['ayes], asigna estas variantes a /i//, según las siguientes razones.

Puesto que en los plurales se considera la variación como morfemática, señala otros ejemplos de variación de [ i ] ], [y] fonética: hoy llegas tarde [i]], hoy es tarde [y]; voy deprisa [i] ], voy enseguida [y]; rey sabio [i ]. rey absoluto [y]. Y agrega (1961/83:156): Está claro que una y otra variante aparecen en los mismos contextos, y por los mismos motivos, que en los ejemplos citados antes de la conjunción y, etc. Si allí admitíamos /i/, aquí, también ${ }^{15}$. 
En algunas posiciones, considera el autor que $/ \mathbf{i} / \mathrm{y} / \mathbf{y} /$ son conmutables, cuando aparecen entre los mismos fonemas, sobre todo en los casos de juntura (o sutura) de morfemas: desierto [-sje-], deshielo [z-dze-]; reniego [-nje-], inyección [-ndze-], abierto [-ßje-], abyecto [-ßdze-], las siervas [la-sjerßas-], las yerbas [lazdzerßas], (...).

Con [j], la consonante precedente forma sílaba; con [y], la consonante precedente resulta final de la sílaba anterior, y si es sorda se sonoriza, como se vio en los ejemplos. Por eso, el autor afirma que lo diferencial en estos casos es la ausencia o presencia de juntura (o sutura) de morfemas.

Respecto de [w] y [ü], la situación se torna un tanto diferente que para [j] e [ i ], pues señala un refuerzo consonántico sólo para $[\mathrm{w}],[\mathrm{gw}]^{16}$, en posición inicial de palabra:

(...) debemos notar que todos los fonetistas están de acuerdo en señalar un refuerzo consonántico de [w] en posición inicial de palabra: hueso [wéso] [gwéso] [gwéso], refuerzo que obliga en el decurso a constituir con [we] una sílaba distinta a la del fonema que preceda: los huesos [loz-wésos] o [loz-gwésos], pero no *[lo-swésos]. Tal situación permite (bien por la articulación consonántica, bien por la presencia de una «juncture», si aceptamos ésta) diferenciar son nuevos [so-nwéßos] de son huevos [son-wé-ßos] (o [so-ngwé-ßos]] e incluso [so-クwéßos]]), haz zuecos [á- $\theta$ wékos] de haz huecos [áz-wékos] (o [ázүwékos]), la suela [la-swéla] de las huela [laz-wéla] (o [lazywéla]), etc.

Alarcos señala que tales variantes reforzadas [yw], [gw] se asemejan en su distribución a las variantes africadas (fuertes) de /y/, mientras [w] y [un] son paralelas a [j] e [i] ; por eso, se deben considerar realizaciones de $/ \mathbf{u} /$.

Para las variantes reforzadas, el autor se pregunta (1961/83:159): ¿tendremos que postular un fonema consonántico independiente $/ w /$, o bien se tratará de sonidos en relación con algún otro fonema consonántico?

El autor (1961/83:164): propone una secuencia $/ \mathbf{g} /+/ \mathbf{u} /$ en posición prenuclear en los siguientes casos: /guéso/, [Уueso] o [weso], hueste /guéste/, [Уueste] o [weste], huerto /guéRto/, [Yuerto] o [werto], guante /guáNte/, guasa /guása/, yegua /yégua/, lengua /léngua/, antiguo /aNtiguo/, etc. Señala, para aclarar su posición difonemática lo siguiente:

El paralelismo con /y/ ha llevado a algunos a considerar estas variantes [ gw ] o [ w ] (distintas del fonema /u/) como realizaciones de un fonema independiente, simbolizado /w/ o/gw/, y no, como hacemos nosotros, de la combinación /g/ + /u/. Que las variantes tipo [ $\mathrm{\gamma} w$ w son difonemáticas, lo demuestra la identidad absoluta de [Y] con las correspondientes variantes del fonema /g/ (con hueso, con guasa y con gasa presentan la misma [g] oclusiva), y la de [w] con las del fonema /u/.

De esta forma, Alarcos concibe que los fonemas existentes son $/ \mathbf{i} /, / \mathbf{y} /, / \mathbf{u} / \mathrm{y} / \mathbf{g} /+/ \mathbf{u} /(\mathbf{g u} /)$.

Esquema-resumen 4. Síntesis Alarcos (1961/83)

1. Concluye que los diptongos carecen de valor monofonemático y son combinaciones de los cinco fonemas vocálicos con otro elemento.

2. Tanto [j], [i] e [i], son variantes combinatorias de /i/, como [w ], [u] y [u], lo son de /u/.

3. Concluye que en todos los casos observados, [j] e [ i ] son realizaciones de /i/, y que es /y/ toda realización que sea [d3] o que en tal contexto pueda alternar con esta. Puede existir variabilidad entre [dz], [y] e incluso [j]. 
... continuación

\section{Esquema-resumen 4. Síntesis Alarcos (1961/83)}

4. Respecto de la alternancia [i] ], [y] en palabras como rey ['rei ], reyes ['reyes]; ay ['aij], ayes ['ayes], asigna estas variantes a /i/.

5. En algunas posiciones, considera el autor que /i/ y /y/ son conmutables, cuando aparecen entre los mismos fonemas, sobre todo en los casos de juntura (o sutura) de morfemas.

6. Respecto de [w] y [un], la situación se torna un tanto diferente que para [j] e [i ], pues señala un refuerzo consonántico sólo para [w], [gw], en posición inicial de palabra. Señala que tales variantes reforzadas $[\mathrm{\gamma w}],[\mathrm{gw}]$ se asemejan en su distribución a las variantes africadas (fuertes) de /y/, mientras [w] y [u ] son paralelas a [j] e [i ]; por eso, se deben considerar realizaciones de /u/. Propone una secuencia $/ \mathrm{g} /+/ \mathbf{u} /$ en posición inicial de palabra (difonemática).

Posteriormente, Cressey (1978) analiza el español desde una perspectiva generativa. Para el autor (1978:26) tanto las semiconsonantes como las semivocales tienen una pronunciación idéntica, por lo que difiere de las afirmaciones de Navarro Tomás respecto de la diferencia de articulación entre [j] e [i]. Plantea, respecto de los núcleos silábicos: I take the position that the systematic phonemic distinction is between a syllabic nucleus [+syl] (a vowel) and a sound that is non-nuclear [-syl] (a glide), and I represent all high glides, whether they appear before or after the syllabic nucleus, simply as [j] and [w].

Para Cressey las deslizadas no forman núcleo de sílaba (son [-silábicas]), como sí lo hacen las vocales [+silábicas].

Respecto de las deslizadas que no son altas, Cressey va más allá de otros autores al decir: I assume that Spanish has potentially five glides, one corresponding to each of the five major vowels. Así, habría cinco vocales plenas y cinco deslizadas correspondientes, como las clasifica en la figura que sigue:

\section{Cuadro 3. Clasificación de todos los segmentos no consonánticos en el nivel fonético amplio}

\begin{tabular}{cc}
\hline [+silábico] & [-silábico] \\
\hline i & j \\
u & w \\
e & e \\
o & o \\
a & a \\
\hline
\end{tabular}

Fuente: Cressey (1978:28) Figura 1.15.

Respecto de los diptongos en las posiciones iniciales de palabra o de morfema, recurre a la propuesta de Navarro Tomás, que señala un segmento [w] en estos casos. Por su parte, 


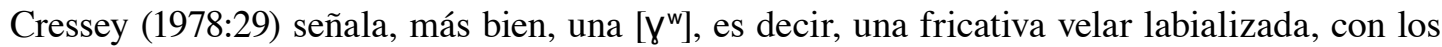
rasgos [+alto, +posterior, +redondeado]. Su análisis fonológico presenta las siguientes reglas de diptongación (1978:47 y ss):
$(2.4)$
[-consonántico, +alto]
[-silábico] /
[+ silábico]
[+ silábico]
(a)
(b)

A los diptongos en posición inicial de sílaba, les sigue en orden la siguiente regla, la cual consonantizaría en obstruyentes los segmentos [-consonánticos, -silábicos], como sigue:

(2.5) [-silábico, -consonántico $] \quad \rightarrow \quad[+$ consonántico, -sonante] / -

Así, las derivaciones de huevo y yerba serían como se muestra en la siguiente figura:

\begin{tabular}{ccc}
\hline & /uebo/ & /ierba/ \\
\hline $\operatorname{Regla}(2.4)$ & $\mathrm{w}$ & $\mathrm{j}$ \\
$\operatorname{Regla}(2.5)$ & $\gamma^{\mathrm{w}}$ & $\mathrm{y}$ \\
& {$\left[\gamma^{\mathrm{w}}\right.$ e $\beta$ o] } & {$[\mathrm{y}$ e r $\beta$ a] } \\
\hline
\end{tabular}

Fuente: Cresssey (1978:50)

Es importante señalar que Cressey parte de que las reglas son ordenadas intrínsecamente en gran medida, es decir, que la aplicación de cada una no depende del orden de aplicación de la serie completa de reglas.

Más adelante, sin embargo, Cressey (1978:77 y ss.) incluye los fonemas /j/ y /w/ en el inventario de los fonemas del español. Esto se debe a que en algunos casos, la distinción entre una deslizada y una vocal alta debe, en algunos casos, especificarse en el lexicón.

Siguiendo a Harris (1969) muestra que el español debe tener una regla de formación de deslizadas que depende de la asignación del acento. Por ejemplo, en los verbos como cambiar, [kámbjo] y en los verbos como ampliar, [amplío], en el primero se representa /j/ como una deslizada fonológica, y en el segundo, /i/. En los casos áureo, náufrago y láudano y ventrílocuo, en cuyos casos no es posible que se asigne el acento en la cuarta vocal de las palabras, se proponen las deslizadas en el nivel fonológico sistemático. Para los casos país [país], paisano [pajsáno] y baúl [baúl] baulero [bawléro], se muestra que los primeros de los dos casos presentan una [i] y una [u] en la superficie, respectivamente, pues el acento se asigna previamente sobre ellas. En los otros casos, las vocales altas en el segundo segmento de cada par se convierten en deslizadas, dado que se encuentran en sílaba inacentuada.

Cressey (1978:78-79) agrega a la interpretación de Harris, que no es necesario representar todo segmento explícitamente como deslizada en el lexicón. Un grupo especial de reglas llamado everywhere rules, se expresan por medio de la marcación; es decir, $u$ (no marcado), y $m$ (marcado). El rasgo silábico en los segmentos deslizados sería [u silábico], 
no marcado o no especificado para el rasgo silábico. En el caso de la u de áureo, esta es marcada [u silábico] en el lexicón, y una everywhere rule especificaría este segmento como [-silábico]. En cambio, las vocales /i / y /u / como en país y baúl, son [m silábico]; es decir, marcadas con el rasgo [silábico].

Por otro lado, las deslizadas fonéticas que derivan de vocales lo hacen por medio de una regla llamada Low Level Allophonic Process Rule. Algunas veces estas se pronuncian como deslizadas y otras como vocales; sin embargo, las deslizadas que se pronuncian siempre como tales, derivan de fonemas deslizados.

Cressey propone entonces dos reglas de formación de deslizadas: una ordenada antes de la regla asignación del acento; la otra ordenada después de la regla de asignación del acento. Hay importantes diferencias respecto de ellas. La primera regla trata con los fonemas deslizados especificados por una everywhere rule. La siguiente regla, la regla variable, trata las deslizadas derivadas de vocales inacentuadas, como en los casos siguientes:

\begin{tabular}{|c|c|c|}
\hline teatro 'theatre' & [te-a-tro], & [tja-tro] \\
\hline poeta 'poet' & [po-e-ta], & [pwe-ta] \\
\hline toalla 'towel' & [to-a-ᄉa], & [twa-ᄉa] \\
\hline mi amor 'my love' & [mi-a-mor], & [mja-mor] \\
\hline tu edad 'your age' & [tu-e- $\delta \mathrm{a} \delta]$, & [twe- $\delta a \delta]$ \\
\hline te adoro ' 1 adore you' & [te-a- $\delta o-r o]$, & [tja- $\delta o-r o]$ \\
\hline
\end{tabular}

Fuente: Cresssey (1978:80)

Las reglas en cuestión serían tal y como aparecen en Cressey (1978:81).

Regla 3.18 de Cressey (p.81). La parte (a) de la regla 3.18 de Cressey indica que el valor más natural no marcado del rasgo silábico es menos (-) en el caso de un segmento no consonántico que sea adyacente a una vocal, y la parte (b) especifica que para todos los otros segmentos no consonánticos, el rasgo no marcado es más (+silábico). Ej. Para (a) áureo; ejemplo para (b) baúl.

La regla variable 3.19 de Cressey establece que una vocal inacentuada se realizará como deslizada en contacto con otra vocal en el siguiente contexto: la operación de la regla se aplicará con mayor posibilidad a la más alta de las vocales, luego a las medias, luego a las bajas; la segunda parte indica que la regla se aplicará más probablemente donde no haya linde o linde morfológico entre los dos segmentos, y menos se aplicará si los dos segmentos están separados por linde de palabra. La aplicación de la regla se bloquea si el linde de frase fonético está presente entre dos vocales.

Finalmente, la regla (3.20) explicará los casos como salieron frente a creyeron de la siguiente manera (Cressey 1978:82): la regla se explicaría señalando que una consonante laxa o aproximante se haría oclusiva después de pausa o después de una nasal o lateral homorgánica. Esto explicaría también el caso de un huevo [uךgweßo]. Esta regla, denominada de espirantización (spirantization of glides) se ordena antes de la de formación de deslizadas. 
Esquema-resumen 5. Síntesis de Cressey (1978)

1. Cressey propone que las deslizadas en español son solamente $[\mathrm{y}] \mathrm{y}[\mathrm{w}]$ en todas las posiciones tanto en diptongos crecientes como en decrecientes.

2. La consonantización en posición inicial de sílaba corresponde a una regla de consonantización que sigue a una regla de desvocalización de dichos segmentos antes o después de vocal.

3. Una regla de espirantización se aplicaría después de pausa o después de una nasal o lateral homorgánica.
4. Cressey propone dos reglas de formación de deslizadas: una ordenada antes de la regla de asignación del acento; la otra ordenada después de la regla de asignación del acento.

a) La primera regla trata con los fonemas deslizados especificados por una everywhere rule.

La siguiente regla, la regla variable, trata las deslizadas derivadas de vocales inacentuadas.

Mosterín (1981:105-115) muestra la siguiente posición respecto de las semivocales y semiconsonantes en español.

El autor señala que, al considerar las vocales $/ \mathbf{i} / \mathrm{y} / \mathbf{u} /$ se plantea el problema de las semivocales, es decir, de los fonos que se parecen (o empiezan o terminan pareciéndose) a /i/ y /u/, pero que no son vocales plenas, pues son incapaces de formar sílaba por sí mismos. El autor propone que esos fonos semivocálicos pueden formar parte del núcleo de una sílaba a base de apoyarse en una vocal plena, a la que preceden o a la que siguen, formando diptongo con ella.

Define el diptongo como un núcleo silábico formado por una semivocal [j] o [w], seguida de una vocal plena (en cuyo caso se habla de diptongo creciente) o por una vocal plena seguida por una semivocal [i] o [ún] (en cuyo caso se habla de diptongo decreciente). Es decir, para Mosterín una semivocal es parte del núcleo silábico y puede tomar la forma tanto de [j] o [w], en diptongos crecientes, como de [i] o [u] en diptongos decrecientes.

Además de estos fonos, el autor distingue en español otros bastante parecidos, pero que son claramente consonánticos y se pronuncian con cierta explosión o fricación del aire al pasar por una estrechez casi total de la boca formada por la lengua apoyada contra el paladar [j] o contra el velo [yw $]^{17}$. Estos fonos consonánticos (o semiconsonantes) se dan en posición inicial de sílaba: [jerba], hierba, [majo]), mayo, [§weko], hueco, [aywekár], ahuecar. En Buenos Aires y en otros dialectos, al fono [ $j$ ], corresponden frecuentemente el fono [3] o [ $]$, según los hablantes.

Mosterín reserva el término semiconsonante a los segmentos dados en posición inicial de palabra o de morfema, como en los casos citados por él anteriormente.

Una parte importante de las reflexiones de Mosterín corresponde a la siguiente pregunta clave: Consideremos ahora la serie de fonos [i], [i ], [j], [j] y la serie de fonos [u], [u్n], [w], [ڤ̌]. ¿Cómo agrupar estos fonos en fonemas? Hay muchas maneras posibles, y casi todas han sido propuestas y defendidas por alguien.

$\mathrm{El}$ autor propone al menos cinco soluciones fonológicas que se han propuesto para tal problema de interpretación.

En primer lugar, se pueden incluir todos los fonos de cada una de las dos series en el mismo fonema. Así, habría dos fonemas: /i/ y /u/, y sería /i/ $=[\mathrm{i}] \cup[\mathrm{i}] \cup[\mathrm{j}] \cup[j]$ $\mathrm{y} / \mathbf{u} /=[\mathrm{u}] \cup[\mathrm{u}] \cup[\mathrm{w}] \cup[\mathrm{yw}]$. Señala que esta es una solución ya adoptada en el siglo XVII por Gonzalo Korreas y propugnada en el siglo XX por Diego Catalán (1964-65) y I. R. Macpherson (1975). 
En segundo lugar, se pueden distinguir en cada serie dos fonemas distintos, uno consonántico y otro que agrupe a las vocales y semivocales. Así, habría cuatro fonemas: /i/, $/ \mathrm{j} /, / \mathbf{u} /, / \mathrm{\gamma w} / \mathrm{y}$ sería $/ \mathbf{i} /=[\mathrm{i}] \cup[\mathrm{i}] \cup[\mathrm{j}], / \mathrm{j} /=[\mathrm{j}], / \mathbf{u} /=[\mathrm{u}] \cup[\mathrm{u}] \cup[\mathrm{w}] \mathrm{y} / \mathrm{\gamma w} /=[$ yw ]. Esta solución es preconizada por H. V. King (1952) (con la salvedad que incluye la [i] final de palabra en $/ j /$ ).

En tercer lugar, se pueden distinguir en cada serie dos fonemas distintos, como en el caso anterior, pero agrupando ahora los fonos de tal modo que en cada serie se reserve un fonema para la vocal plena y se agrupen los demás fonos no plenamente vocálicos en un fonema aparte. Así, habría 4 fonemas $/ \mathbf{i} /, / \mathbf{j} /, / \mathbf{u} /, / \mathbf{w} /$, y sería $/ \mathbf{i} /=[$ i $], / \mathbf{j} /=[\mathrm{i}] \cup[\mathbf{j}] \cup[j]$, $/ \mathrm{u} /=[\mathrm{u}] \mathrm{y} / \mathrm{w} /=\left[\mathrm{u}_{n}\right] \cup[\mathrm{w}] \cup[\mathrm{yw}]$. Esta solución es preconizada por J. O. Bowen \& R.P. Stockwell (1955) y por J. O. Bowen, R.P. Stockwell \& J. Silva-Fuenzalida (1956).

En cuarto lugar, se puede adoptar una solución intermedia entre la primera y la segunda, separando fonemáticamente el fono consonántico de los vocálicos y semivocálicos en la primera serie, pero agrupando a todos los fonos de la segunda serie en un solo fonema. Así, habría 3 fonemas: $/ \mathbf{i} /, / \mathbf{j} /, / \mathbf{u} /$, y sería $/ \mathbf{i} /=[i] \cup[i] \cup[j]$ y $/ \mathbf{j} /=[j]$ y $/ \mathbf{u} /=[\mathrm{u}] \cup[\mathrm{u}] \cup[\mathrm{w}] \cup[\mathrm{\gamma w}]$. El autor señala que esta es casi la solución preconizada por E. Alarcos Llorach (1950/65) (con la

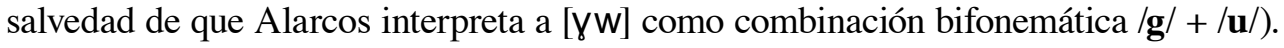

El autor señala que se podría negar el análisis de los diptongos en fonemas más simples, considerando más bien que cada combinación de vocal y semivocal (o de semivocal y vocal) es un fonema independiente. En tal caso habría, además de /i/ y de /u/, un fonema para cada uno de los diptongos antes examinados: /je/, /ja/, etc. Esta es la posición adoptada por T. Navarro Tomás (1946).

De este modo, Mosterín (1981:109-110) se refiere a la multiplicidad de los enfoques metodológicos en este punto no solo para el español, sino también para otras lenguas romances, como el francés, el italiano y el portugués. Fuera de ellas, menciona también discusiones sobre los diptongos del inglés.

Ahora bien, el autor pretende una reforma ortográfica del español que sea fonemática; sin embargo, no es su preocupación fundamental ahondar en el debate teórico de fondo. Desea aplicar el principio fonológico a la escritura, por lo que considera que las soluciones segunda y cuarta son congruentes con dicho principio.

Considera que la ortografía fonemática debería ser como sigue:

Cuadro 4. Ortografía fonemática propuesta por Mosterín para / $i$ / y / j /

\begin{tabular}{cc}
\hline Fonema & Letra \\
\hline$/ \mathbf{i} /:[\mathrm{i}],[\mathrm{i}],[\mathrm{j}]$ & $\mathrm{i}$ \\
$/ \mathrm{j} /$ & $\mathrm{y}$ \\
{$[\mathrm{i}]$ final de palabra } & y \\
{$[i[\mathrm{i}]$ de los diptongos decrecientes } & i \\
\hline
\end{tabular}

Fuente: Propia 
CALVO: Las semiconsonantes y semivocales en los diptongos del español: propuesta de...

Mosterín (1981:113) es congruente con la idea de presentar un paralelismo entre / j / y / w̌ /; por tanto, considera la siguiente propuesta.

Cuadro 5. Ortografía fonemática propuesta por Mosterín para / u / y / ̌̌ /

\begin{tabular}{cc}
\hline Fonema & Letra \\
\hline$/ \mathbf{u} /:[\mathrm{u}],[\mathrm{u}],[\mathrm{w}]$ & $\mathrm{u}$ \\
$/ \mathbf{w} /:[\mathrm{\gamma w}]$ & $\mathrm{w}$ \\
\hline
\end{tabular}

Fuente: Propia

Como el autor también propone la eliminación de h, los siguientes ejemplos dan lugar a la aplicación de su ortografía fonemática:

\begin{tabular}{cl}
\multicolumn{2}{c}{ Cuadro 6. Ejemplos de aplicación } \\
de la ortografía fonemática & de Mosterín (1981) \\
\hline yerba & weso \\
yelo & deswesar \\
yedra & wérfano \\
adyero ${ }^{18}$ & weko \\
reino & awekar \\
rey & \\
\hline
\end{tabular}

Fuente: Propia

Así pues, con el fin de optimizar la escritura del español, el autor idea una reforma de ortografía fonémica (fonemática) basada en el principio fonológico, que exige una correspondencia biunívoca entre las secuencias de fonemas y las letras correspondientes; sin embargo, como lo señala, no profundiza en el debate teórico que aquí interesa, por lo que quedan sin resolver las dificultades de análisis fonológico que son objeto en este estudio.

Esquema-resumen 6. Síntesis de Mosterín (1981)

1. El autor propone que las semivocales pueden formar parte del núcleo de una sílaba a base de apoyarse en una vocal plena.

2. Además de estos fonos, el autor distingue en español otros bastante parecidos, pero que son claramente consonánticos y se pronuncian con cierta explosión o fricación del aire al pasar por una estrechez casi total de la boca formada por la lengua apoyada contra el paladar [ $j] \mathrm{o}$ contra el velo [yw].

3. Con el fin de optimizar la escritura del español, el autor idea una reforma de ortografía fonemática basada en el principio fonológico, que exige una correspondencia biunívoca entre las secuencias de fonemas y las letras correspondientes; sin embargo, no profundiza en el debate teórico que aquí interesa, por lo que quedan sin resolver las dificultades de análisis fonológico que son objeto en este estudio. 
D'Introno y otros (1995:208) presentan las siguientes interrogantes respecto del tema de las deslizadas:

\begin{abstract}
Un tema que aún no hemos abordado es cuáles son los fonemas que subyacen a las deslizadas. La respuesta a esta pregunta puede ser que las deslizadas se deriven de fonemas deslizados subyacentes, es decir, /j, w/, o bien que las deslizadas se deriven de los fonemas vocálicos altos /i, u/. Podemos inclusive pensar que en algunos casos se derivan de fonemas deslizados y en otros casos de fonemas vocálicos. ¿Cuál de estas posibilidades es la correcta?
\end{abstract}

Inician señalando que la diferencia fonética entre una semivocal y su correspondiente semiconsonante se debe a la posición que cada una ocupa dentro del diptongo y que esta es de poca relevancia para un análisis fonológico. De esta forma, las representan con un mismo símbolo: [j] para la deslizada anterior, y [w] para la deslizada posterior.

Respecto de las palabras suave o piano ${ }^{19}$ (1995:211-212), que pueden pronunciarse tanto como s[wá]ve o s[u\$á]ve y como p[j]ano o p[i]ano, se preguntan cuál sería la representación fonológica de ambas palabras, o bien una deslizada que se vocaliza, o bien una vocal que se desliza. La primera opción es poco económica porque requeriría dos reglas: una de vocalización y otra de inserción de un límite silábico entre vocales.

Por su parte la segunda, requeriría la elisión de límite silábico y luego se aplicaría la regla de deslizamiento, lo cual no requeriría agregar una nueva regla sobre el límite silábico. Esto lo describen como regla 3., a saber $\$ \rightarrow \varnothing / \mathrm{C}$ $\mathrm{V}$, y luego una regla que más abajo describirán como 8., cuyo primer contexto se aplicaría a estos casos:

$$
\underset{[\text { alta }]}{\mathrm{V} \rightarrow \mathrm{D} /{ }^{-} \mathrm{V}}
$$

Respecto de las palabras como cantáis (1995:212-213), un segundo argumento favorecería la hipótesis de que las deslizadas se derivan de vocales. Puesto que la regla general del acento primario en español hace que este se coloque en la penúltima sílaba, si se supone que la estructura fonológica es / $\mathrm{kan} \$$ ta\$is/, la regla de acentuación se aplicará a la penúltima sílaba, ta, y luego actuaría el deslizamiento y se obtendría el resultado deseado. De lo contrario, si la estructura fonológica fuera con deslizada, complicaría el análisis.

Respecto de las palabras como tribu y casi (1995:213), un tercer argumento favorecería de nuevo la hipótesis del deslizamiento. Si estas van seguidas de una palabra que empieza por vocal, como tribu ingrata y casi apagado, estas /u/ e /i/ se realizan como [w] y como [j], respectivamente, formando sílaba con la vocal siguiente. Así, las reglas de deslizamiento de vocales se postulan en D'Introno y otros (1995:213) como sigue:

8

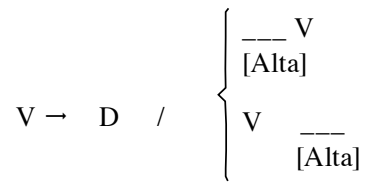

9 .

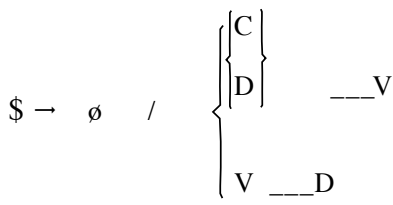


Estas dos reglas representan el proceso; en 8 se formula la regla de deslizamiento, y en 9. la elisión de linde silábico.

Para los casos de palabras como láico, jáula, réina, néutro, heróico, bóu, en que la vocal plena del diptongo es la vocal acentuada, estas tendrían también una estructura fonológica de dos vocales con regla de deslizamiento, en el contexto interior de palabra con la segunda vocal alta, aplicable antes de la regla de acentuación por defecto.

Para explicar la consonantización de las deslizadas, los autores recurren a la estructura silábica. Dentro de las razones para justificar la estructura jerarquizada de la sílaba con núcleo y margen prenuclear, está la de la consonantización de las deslizadas que forman diptongo en posición inicial de palabra, lo cual presenta un constituyente prenuclear (1995:235):

\footnotetext{
Un proceso que revela la existencia de un constituyente prenuclear, porque afecta a este constituyente independientemente de la vocal, es el de la consonantización de una deslizada prenuclear. Por ejemplo la palabra "huevo" se pronuncia en algunos dialectos con una velar inicial, por consonantización de la deslizada [w]: [gw]evo. Ahora bien, este proceso afecta al "constituyente" prenuclear porque, como veremos más tarde, el tipo de consonantización depende del tipo de la deslizada presente. En otros términos la deslizada da origen a una consonante que comparte ciertas características con la deslizada, de modo que ambos, deslizada y consonante, forman parte de un constituyente prenuclear.
}

Otra de las preguntas de estos autores respecto del tema es la siguiente (1995:237): (...) cuando una vocal se desliza, ¿a qué parte o a qué constituyente de la nueva estructura silábica se adjunta? Su hipótesis es que la deslizada no se adjunta al núcleo. Sus razones son tres. Primero, (1995:238) que existe un proceso de consonantización que puede afectar a una deslizada prenuclear: la deslizada "crea” una consonante. Así, la deslizada y la consonante resultante forman parte de un mismo constituyente, y no tendría explicación satisfactoria si la deslizada se adjuntara al Núcleo silábico, (...).

Segundo, (1995:239) que la deslizada es originalmente una vocal que resilabea cuando una sílaba tiene un ataque vacío, lo cual hace que dicha vocal se convierta en un ataque no vocálico. Los autores señalan que el resilabeo es una regla general que se aplica tanto a consonantes como a vocales, lo cual impediría que una deslizada prenuclear resilabee juntándose al núcleo, mientras una consonante se resilabee formando ataque.

Tercero, si se tiene la sílaba [mi] seguida de una vocal no alta, esta puede resilabearse y convertirse en una deslizada: [mj]. Puesto que esta es un constituyente, estos miembros se mantienen unidos después del resilabeo. Esto solo es posible si la sílaba se convierte en un ataque sin dividirse. [A $\mathrm{mj}]$ sin dividirse.

Lo anterior justifica lo que se refiere a las deslizadas en posición prenuclear. Respecto de las deslizadas postnucleares, las estructuras anteriores no corresponden, puesto que esta no se consonantiza. Sin embargo, siempre favorecen su hipótesis basándose en la reinterpretación de la resilabificación de la sílaba (1995:239):

\footnotetext{
(...) si la deslizada posnuclear forma originalmente parte de una sílaba constituida de una vocal alta y una consonante, como por ejemplo, in de in\$fierno, y la vocal se resilabea, junto con la deslizada, como por ejemplo en negr[oj]n\$fierno. Lo que en nuestra opinión muestra que la deslizada y la consonante que originalmente forman una sílaba siguen formando un constituyente después del resilabeo, esto es una Rima. Este argumento nos permite concluir que la deslizada posnuclear no se adjunta al Núcleo vocálico sino a una proyección de $\mathrm{S}$.
}

Respecto de la consonantización de las deslizadas, como pueden ser los casos siguientes: vo\$[y] a \$ morir o mu\$[y] al\$to, la condición para que la deslizada se consonantice, es que esta 
aparezca a inicio de sílaba, sin que esté precedida de consonante, pues no se consonantizaría, como en s[j]es\$cucho. Esta condición es necesaria puesto que, de acuerdo con su hipótesis, el Ataque es un constituyente constante de la sílaba, al igual que el, Núcleo vocálico, y a nivel fonológico contiene C. La sílaba por excelencia sería, entonces, constituida por CV (1995:242).

Posteriormente se preguntan (1995:244): ¿Qué pasa en el caso de un ataque que contiene una deslizada y una $C$ vacía? En este caso, $\mathrm{C}$ rige-A a la deslizada y no es regida -A por esta. Al no estar regida-A , C debe estar fonéticamente llena, es decir, la posición C deberá estar llenada de rasgos. En este caso, la posición C se llena de rasgos gracias a un proceso de expansión de los rasgos de la deslizada, de modo que los rasgos especifican simultáneamente a la deslizada y a la consonante, como en el caso de 35a. Ej. p. 245:

$35 \mathrm{a}$.

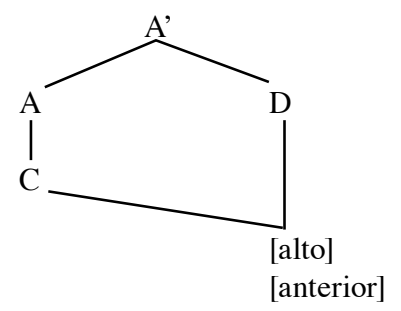

$35 b$.

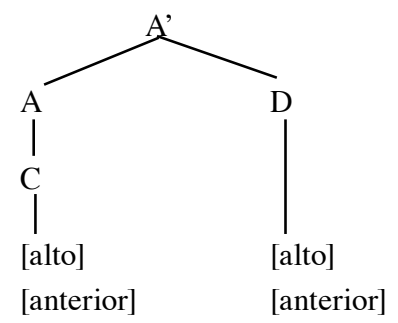

Esto da lugar a la pronunciación de [j]. Si se pronuncia con una consonante prepalatal, que para los autores se simboliza [y] se obtiene independizando la consonante de la deslizada, como se nota en 35b. Según los autores, en esta pronunciación el efecto fonético de la deslizada queda neutralizado por [y] (1995:246). Para ellos, es posible que la realización consonántica de la deslizada requiera la ausencia de límite de palabra detrás de la deslizada, por eso es probable que para los hablantes las pronunciaciones vo $\$[\mathrm{j}]$ a $\$$ morir o mu\$[j] al\$to, con deslizada, sean las únicas posibles.

Esto lleva a la pronunciación de las palabras re[j] y re[y]es, le[j] y le[y]es, que correspondería a la consonantización de la deslizada en el contexto \$___ obligatoriamente, donde no va seguida del símbolo \#, pero opcional, si va seguida de \#.

Luego, según los autores, la consonantización de los diptongos en posición inicial confirman su conclusión, a saber las palabras hierro, hielo, hierba, etc. se articulan con una [y] (según los autores) al comienzo de palabra (o con [j ] si aparecen por ejemplo después de pausa). La pregunta en este punto es (1995:247): ¿Se deriva este segmento de la deslizada [j]? La respuesta es sí, por las razones siguientes.

Señalan que en español no existe una palabra que empiece con la deslizada [j], por la siguiente razón. El lexema de las palabras hierro, hielo, hierba, etc., alterna con herramienta, hel-ado, herb-ívoro, respectivamente, que tiene una vocal [e]. Esta alternancia está relacionada con el acento: en hierro, por ejemplo, el acento recae sobre la vocal del lexema, en herramienta, sobre el sufijo. Los autores señalan como única explicación plausible para esta 
alternancia es que el lexema de estas palabras tenga a nivel fonológico una vocal /e/. Si la /e/ lleva acento, diptonga en [jé] debido a Diptongación, dando por ejemplo hierro. Después de esto la deslizada, al encontrarse a comienzo de sílaba y al no estar seguida de límite de palabra, se convierte (obligatoriamente) en $[j]^{20}$.

Para los autores esto no incluye la [j] de yacimiento, yugo, yogurt, Yolanda, yegua, etc., puesto que no se derivan de una deslizada; primero, porque no hay diptongación en estos casos, y segundo, porque no se pronuncian con $[\mathrm{j}]$.

De este análisis surge un problema, a la hora de analizar la pronunciación de deshielo como des[j]elo.

Si la representación fonológica de esta palabra es des/e/lo, que luego por acentuación y diptongación pasa a des[jé]lo, aquí la /s/ debería formar parte de la sílaba s[jé] y debería impedir la consonantización de la deslizada, así que la pronunciación definitiva debería resultar des[jé]lo. Pero según los autores, esto no sucede. La razón de ello es que la /s/ no forma parte de esa sílaba, pues la silabificación de deshielo es des\$[jé]\$lo. Pero ahora cabe preguntarse por qué la /s/ no forma parte del Ataque de la sílaba siguiente, junto con la deslizada.

La palabra deshielo está constituida de la palabra hielo y el prefijo des-. de manera que la estructura morfofonológica de deshielo es esencialmente la que se ofrece en (36a), representada gráficamente en (36b).

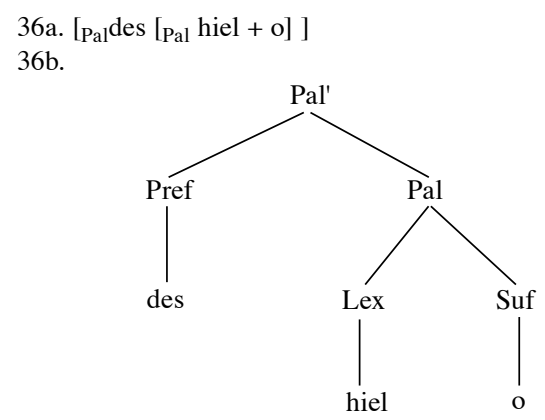

Esquema-resumen 7. Síntesis D’Introno y otros (1995)

1. Los fonemas que subyacen a las deslizadas son vocálicos.

2. La condición para que una deslizada se consonantice, es que esta aparezca a inicio de sílaba, sin que esté precedida de consonante, pues no se consonantizaría. Esta condición es necesaria puesto que el Ataque es un constituyente constante de la sílaba, al igual que el Núcleo vocálico, y a nivel fonológico contiene C. La sílaba por excelencia sería, entonces, constituida por CV. La deslizada es originalmente una vocal que resilabea cuando una sílaba tiene un ataque vacío, lo cual hace que dicha vocal se convierta en un ataque no vocálico.

3. El lexema de las palabras hierro, hielo, hierba, etc., alterna con herr-amienta, hel-ado, herb-ívoro, respectivamente, que tiene una vocal [e]. El lexema de estas palabras tiene a nivel fonológico una vocal /e/. Si la /e/ lleva acento, diptonga en [jé] debido a Diptongación, dando por ejemplo hierro. Después de esto la deslizada, al encontrarse a comienzo de sílaba y al no estar seguida de límite de palabra, se convierte (obligatoriamente) en [j].

4. Esto no incluye la [j] de yacimiento, yugo, yogurt, Yolanda, yegua, etc., puesto que no se derivan de una deslizada; primero, porque no hay diptongación en estos casos, y segundo, porque no se pronuncian con $[\mathrm{j}]$. 
NúñezCedeñoy Morales Front(1999:173-175) presentan una primera pregunta(1999:173) en la que señalan lo siguiente: Las deslizadas en posición prevocálica (semiconsonantes) presentan un problema especial. ¿Son parte del ataque o de la rima?

A partir de varios argumentos, concluyen que las deslizadas no forman grupo de ataque silábico con la consonante precedente, sino que son parte de la rima.

Los autores señalan cuatro argumentos con los que tratan de comprobar su propuesta, y una excepción.

El primer argumento corresponde a la división silábica de un juego infantil de palabras denominado jerigonza, en el que se separan las vocales de los diptongos como si ambas correspondieran a núcleos diferentes:

(...) En este juego pasa se transforma en pa-ka-sa-ka y están en e-kes-ta-kan. Los grupos de ataque como/pr/, /pl/, nunca se dividen en este juego: proclama es pro-ko-cla-ka-ma-ka. Por el contrario, vemos que puente es pu-ku-e-ken-te-ke y tiene es ti-ki-e-ke-ne-ke. Igual tratamiento reciben los diptongos decrecientes: peine es pe-ke-i-ki-ne-ke. Lo que demuestra este juego (ju-ku-e-ke-go-ko) es que en la intuición de los hablantes /pwe/ y /pre/, por ejemplo, tienen estructuras radicalmente diferentes. Las deslizadas (incluyendo las llamadas semiconsonantes) claramente se relacionan con las vocales más estrechamente que con las líquidas. El juego al que hemos aludido puede resumirse como inserción de kV detrás de cada vocoide (vocal o deslizada) donde V es una copia del vocoide precedente.

El segundo argumento tiene que ver con la formación de hipocorísticos que, según los autores, incluye el elemento deslizado del diptongo: A este respecto podemos señalar también que el proceso de abreviación familiar que nos permite formar Fede a partir de Federico o profe a partir de profesor, produce Dani de Dan[je]l mientras que una forma familiar de Petronio puede ser Petro, pero obviamente no *Petr (...).

El tercer argumento tiene que ver con el propuesto por Harris (1983), respecto de la complejidad posible de la rima:

\footnotetext{
Parece que en español la rima no puede contener más de tres segmentos en total. No tenemos palabras como *auns.tral, cuya primera sílaba contendría una rima de cuatro segmentos. Pues bien, en esta computación de tres segmentos en la rima debemos incluir también las semivocales prevocálicas, dado que tampoco podemos tener palabras como *muens.tra.
}

El cuarto argumento se refiere a un dialecto del español hablado en el Valle de Pas (Cantabria) que presenta un condicionamiento de armonía vocálica debido a las deslizadas prevocálicas:

\footnotetext{
También podemos notar que en un dialecto (o co-dialecto) del español como el hablado en el Valle de Pas (Cantabria), con armonía vocálica, las deslizadas prevocálicas se comportan como parte del núcleo en cuanto condicionan el proceso de armonía (cf. Hualde 1991): mi lu djó vs. me lo compro. por ejemplo. Todo esto nos lleva a concluir que las deslizadas no forman grupo de ataque silábico con la consonante precedente, sino que son parte de la rima.
}

La excepción tiene que ver con las deslizadas en posición inicial de palabra, sin que preceda una consonante, como en hielo, hueso. En este caso, ocuparían el ataque de la sílaba, como se observa en su frecuente consonantización [jélo], [wéso]. Otros casos de consonantización serían en relación con la asimilación de nasales: [uñdzélo], [ungwéso] y tras prefijos productivos como des- en des.hie.lo, que comparan con de.sier.to, y re.sue.na con des.hue.sa.

Respecto de su estatus fonológico, los autores señalan (1999:183) que en español existe un contraste fonémico (fonológico) entre vocales y deslizadas. Lo comprueban por medio de al menos tres argumentos. El primero de ellos es que en español existen algunos hiatos que no ofrecen ninguna explicación para que lo sean: 
(...) para muchos hablantes, aunque al parecer no para todos, hay palabras que excepcionalmente tienen hiato sin que exista ninguna explicación morfológica para ello. Por ejemplo, mientras que diente, mientras, vientre, siente, tiene tienen un diptongo [je], hay muchos hablantes para quienes la palabra cliente es diferente de las otras y contiene un hiato: [kIi.én.te]. Del mismo modo, la situación más común es que /iá/, /uá/ formen un diptongo, como en Sant[já]go, ac[já]go, liv[já]no, c[wá]ndo, etc, pero en palabras como d[i.á]blo, R[u.á]nda, podemos encontrar un hiato, constituyendo estas palabras la excepción a la norma general (véase Real Academia 1983:47-58).

Por tales razones los autores concluyen (1999:183), que en español existe un contraste fonólogico entre vocales y deslizadas. De todas formas, cuando el acento no cae sobre la vocal alta, las palabras con hiato son la excepción y encontramos variación dialectal en cuanto a qué palabras permiten la pronunciación en hiato.

En (21) los autores anotan algunas palabras que ejemplifican el contraste diptongo/ hiato para hablantes de variedades del norte y centro de España:

\begin{tabular}{|c|c|c|c|}
\hline & Diptongo & & hiato \\
\hline \multirow[t]{2}{*}{ [já] } & asiático & [i.á] & piano \\
\hline & mediante & & Viana \\
\hline \multirow[t]{4}{*}{ [jé] } & miel & [i.é] & riel \\
\hline & diente & & cliente \\
\hline & barriendo & & riendo \\
\hline & pie & & pié (piar) \\
\hline \multirow[t]{3}{*}{ [jó] } & dio & [i.ó] & rió \\
\hline & precioso & & biombo \\
\hline & radiólogo & & biólogo \\
\hline \multirow[t]{2}{*}{ [jú] } & viuda & [i.ú] & diurno \\
\hline & & & multiuso \\
\hline \multirow[t]{2}{*}{ [wá] } & cuando & [u.á] & Ruanda \\
\hline & Juana & & roana \\
\hline \multirow[t]{2}{*}{ [wé] } & duelo & [u.é] & dueto \\
\hline & puente & & \\
\hline ب́ & cuota & [u.ó] & presuntuoso \\
\hline ) & fuimos & [u.í) & huimos \\
\hline & cuita & & jesuita \\
\hline
\end{tabular}

El segundo sería el argumento de la realización acústica del contraste, que lo proponen citando a Quilis (1981:179), el cual manifiesta la producción de un tránsito lento frente a uno rápido, si se trata de un diptongo o de un hiato:

En cuanto a la realización acústica de este contraste, Quilis (1981: 179), comparando ejemplos tales como [pjé] y [pi.é] (del verbo piar), nos dice que "se produce un cambio lento de la transición entre los formantes 
de las dos vocales cuando forman grupo tautosilábico; por el contrario, un cambio refleja una secuencia heterosilábica, siendo tanto más acusada la percepción de hiato cuanto más rápido sea el cambio, ya que éste actúa como límite silábico.” Quilis (1981: 180-184) ofrece espectrogramas comparando pares secuencias en diptongo e hiato tales como c[wá]tro vs. sit[u.á]do, c[wí]da vs. h[u.í]da y v[jú]da vs. d[i. ú]rmo. El contraste en la realización fonética del diptongo en está barr[jé]ndo y el hiato de estaba r[i.én]do se ilustra en Monroy Casas (1980: 116).

Otro argumento que presentan los autores (1999:184-185) es el del acento, desde posiciones distintas, y de este se desprende el de los segmentos moraicos ${ }^{21}$ :

Otros argumentos dados para establecer una distinción subyacente entre vocales altas y semivocales tienen que ver con la distribución del acento (Harris 1969). (...) Estos argumentos, al contrario de los hechos que acabamos de considerar, tienen mayor o menor fuerza según el modelo teórico que adoptemos. En primer lugar, si presumimos que en español el acento se mediante una regla o sistema de reglas, en una palabra como sáurio, no todos los vocoides podrían ser subyacentemente silábicos, dado que el acento en español no puede caer más allá de la antepenúltima sílaba. Este argumento, naturalmente, se desvanece si rechazamos el modelo clásico generativo con reglas ordenadas y etapas intermedias en la derivación. Si por el contrario suponemos que el acento es una propiedad esencial (subyacente) de las entradas léxicas y que la "ventana de tres sílabas" para la colocación del acento es una restricción que se aplica a la forma superficial, lo único importante es que esta restricción se respeta en la forma superficial de sáurio.

El argumento sobre las estructuras moraicas favorece su propuesta y explica el porqué los fonemas /j/ /w/ no están asociados a tal estructura:

En el modelo moraico tanto las vocales altas /i/, /u/, como las deslizadas /j//w/ tienen los mismos rasgos segmentales y difieren en que $/ \mathrm{i} /$, /u/ tienen una mora asociada, mientras que $/ \mathrm{j} /$, / $/ \mathrm{w}$ no la tienen. Por ejemplo d[je]nte y cl[ie]nte tienen diferente estructura moraica (y, consecuentemente, silábica) para hablantes con este contraste léxico:

(22) Segmentos moraicos y no moraicos

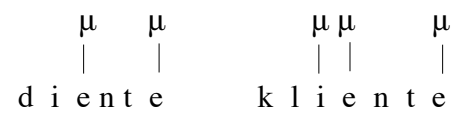

explicación que presentan es que, en general, una vocal alta no acentuada en contacto con otra vocal no es moraico (es decir, es una deslizada). Señalan que casos como los de [kli. én.te] son excepcionales, puesto que, según los autores, (...) La tendencia a evitar los hiatos es una manifestacion del principio de arranque obligatorio, dado que una secuencia en hiato supone la existencia de una sílaba sin arranque.

Así mismo, lo que los autores llaman un factor de complicación, es que las vocales altas pueden realizarse como deslizadas más allá de los límites de una palabra, a nivel postléxico. Así, mientras que en Jua.n [i]. Ma.rí.a tenemos una vocal, en Pe.dro[j]. Ma.rí. a tenemos una semivocal. Compárense también por ejemplo, t[u].pa.dre y t[w] a. bue.lo. Es decir, una vocal puede perder su mora asociada en ciertos contextos.

Respecto de aquellos contextos en que las vocales pueden perder su mora asociada, son los procesos de resilabificación a través de fronteras de palabras. Así, una consonante final de palabra puede resilabificarse como ataque cuando va seguida por otra palabra que empiece por vocal, también hay resilabificación en secuencias vocálicas, lo cual se conoce como sinalefa.

Los autores presentan (1999:186) los siguientes ejemplos: 
Se ha presentado en esta sección una cronología de hipótesis según diversas posiciones teóricas sobre el estatus fonológico de los segmentos semiconsonánticos [j] y [w] en español. A continuación, se elegirá una de estas propuestas como la más adecuada para explicar dicho fenómeno, sin restar mérito a la contribución de todo el aparato teórico que ha aportado distintos modelos que pretenden poseer un alto grado de generalidad.

\section{Conceptualización teórica adoptada en este estudio y propuesta metodológica}

Este estudio se muestra a favor de una explicación fonológica que explique los procesos no solo desde la perspectiva de los segmentos (congruencia del modelo de la corriente estructuralista, que estudia los sistemas fonológicos propios y únicos de cada lengua como paradigmas organizados en oposiciones distintivas), sino también desde la sílaba, tal y como los explica la fonología contemporánea del tipo CV.

En esta investigación se mantiene la posición de que una interpretación fonológica sobre este fenómeno se sostiene mejor a partir de la estructura silábica, la cual puede ser llenada por distintos rasgos de acuerdo con procesos de expansión, resilabificación y proyección.

Respecto de la sílaba ${ }^{22}$, se puede definir como un conjunto de segmentos agrupados en torno a un núcleo, que en español está constituido por una vocal. Los segmentos dentro de la sílaba se caracterizan por medio de una escala de sonoridad, de modo que el segmento con mayor sonoridad ocupa el lugar central en la sílaba (el núcleo) y los otros segmentos a su izquierda o derecha descienden progresivamente en sonoridad.

Es decir, existe un principio de secuencia de sonoridad que, según Clements (1990:1) señala, no es nada nuevo: Principles such as the Sonority Sequencing Principle, introduced as early as the 19th century by Sievers (1881), and later by Jespersen (1904), explains, for instance, the tendency, within a syllable, of more sonorous segments to stand closer to the syllable peak than less sonorous ones. La escala de sonoridad es la siguiente, su distribución en la sílaba y el valor de cada segmento según su posición en la escala:

Cuadro 7. Escala de sonoridad

\begin{tabular}{|c|c|c|}
\hline (1) VOCALES (V) & $\begin{array}{l}\text { (2) } \mathrm{m} \text { u e } \mathrm{s}-\mathrm{tr} \text { a n } \\
\text { NDVO O LVN }\end{array}$ & $\begin{array}{l}\text { (3) } V=5 \\
\text { a. }\end{array}$ \\
\hline DESLIZADAS (D) & $\begin{array}{l}\text { pe r s }- \text { pe } k-t i-b \text { a } \\
\text { OVLO OVO OV OV }\end{array}$ & $\mathrm{D}=4$ \\
\hline LÍQUIDAS (L) & & $\mathrm{L}=3$ \\
\hline NASALES (N) & & $\mathrm{N}=2$ \\
\hline OBSTRUYENTES (O) & & $\mathrm{O}=1$ \\
\hline
\end{tabular}

Fuente: Núñez Cedeño y Morales-Front (1999:170-171)

Asignando el número a los segmentos según su posición en la escala, se nota que el valor de los segmentos disminuye conforme se alejan del núcleo: 


\begin{tabular}{cl}
\hline b. mue s-t r a n & pers - pe k-t i-b a \\
NDVO OL V N & OVLO OVO OV OV \\
24511352 & 15311511515 \\
\hline
\end{tabular}

Fuente: Núñez Cedeño y Morales-Front (1999: 171)

Para referirse a posiciones o a grupos de segmentos en la sílaba se utilizan los términos núcleo, ataque, coda y rima. Estos términos definen estructuras como la que se ilustra en Núñez Cedeño y Morales-Front (1999: 173) para la representación de la sílaba plan:

(4)

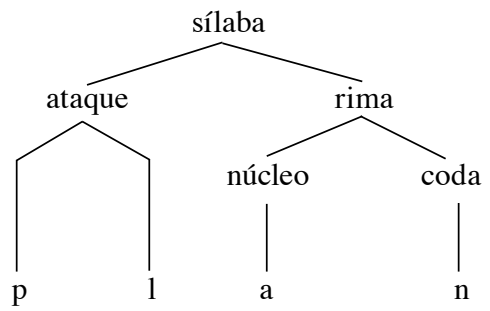

Los autores señalan que la única dificultad en establecer el número de sílabas en español corresponde a la silabificación de secuencias de vocoides (vocales y deslizadas) como ai, iu, ue, puesto que pueden realizarse como vocales en dos sílabas separadas, [a.i.], [i.u.], [e.o.], o uno de ellos puede ser una deslizada y la secuencia pertenecería a una sola sílaba como en [aj], [ju], [ew].

Después de los planteamientos presentados anteriormente, se propone lo siguiente:

La cuestión de si las deslizadas son parte del núcleo o de los márgenes silábicos es verdaderamente relevante ya que, si se observa la escala de sonoridad anteriormente presentada, se nota que estas presentan, en la escala de valores, un 4, que es el más cercano al de las vocales, con valor de 5 .

En esta investigación se concuerda con D'Introno y otros (1995) en que estos segmentos no forman núcleo silábico con la vocal del diptongo, puesto que las deslizadas en posición inicial de palabra, como en hielo, hueso, pueden ocupar el ataque de la sílaba, tal y como se observa en su consonantización [dzélo - zélo - jélo], [gwéso - ywéso - wéso].

A este respecto, sin embargo, vale señalar que la autora no ha encontrado, en los diptongos iniciados con posición inicial, gran cantidad de consonantizaciones, desde la perspectiva fonológica de que las consonantes son, únicamente, las obstruyentes. Se han encontrado, en su mayoría, variantes semiconsonantes (sonantes).

Las deslizadas se producen a partir de los fonemas vocálicos altos /i, u/. El hecho de que los diptongos puedan desasociarse en ocasiones corrobora esta hipótesis; por ejemplo, cuando se realiza un linde silábico entre ellos por asignación del acento: ['dja.ßlo] frente a [di.'a.blo] 'diablo', o entre [kons.tru.'ir] y [kons.'trwir] 'construir'. En diptongos en posición inicial de palabra, hay también una vocal, a saber, /i/, /u/ que se desliza por contacto con la vocal plena y, en un proceso de resilabificación, la deslizada se puede convertir en una consonante prenuclear. Se concuerda con Navarro Tomás (1946) en que en la pronunciación esmerada (cuidadosa), por influencia de la escritura, se articulan como semiconsonantes. 
El hecho de que el habla del español actualmente no sea muy prolija en consonantizaciones de tipo obstruyente en posición inicial, es un argumento en favor de la hipótesis de que no hay cuatro fonemas en esta variedad, a saber /j/, /w/, /i/, /u/, sino dos, /i/, /u/.

\section{Metodología}

Respecto de los datos utilizados para la investigación en fonética y fonología (Llisterri, J. (1992)) en relación con el "habla espontánea", se entrevistó a siete hablantes del español de San José, Costa Rica (tres mujeres y cuatro hombres, adultos, con estudios de secundaria completa) entre los 22 y los 38 años, y se les solicitó, sobre la base de un cuestionario, la elicitación de diecisiete palabras a partir de ilustraciones: seis que inician con diptongo, huevo, hierro, hueco, huesos, hielo, hierba; cinco palabras con diptongos crecientes, diente, diablo, puerto, guaria, lluvia; cuatro palabras con diptongos decrecientes, bailar, maullar, y dos palabras con los hiatos e.a, e.o, vía láctea, leopardo. No se tomaron en cuenta estilos lingüísticos, considerando que el estudio de Aguilar y Machuca (1995) no arrojó resultados significativos que se relacionaran con los estilos lingüísticos o factores pragmáticos respecto de las propiedades fonéticas de los diptongos y los hiatos en español:

In order to determine if the observed differences are significant from a statistical point of view, a two-way ANOVA analysis was applied to the data. There were no significant effects due to the intentionality of the speech acto $r$ familiarity across the range of categories $(\mathrm{p}>0.05)$.

Tampoco se tomaron en cuenta factores sociolingüísticos pues no es el interés primordial de este estudio hacer diferencias por edad, sexo o estatus social, aunque no se descarta que estas diferencias puedan existir. Se grabaron ejemplos en condiciones de laboratorio, siguiendo a Llisterri, J. (1992:3), quien señala que, what is labelled as "spontaneous speech" has been in most cases obtained in a quite constrained situation, i.e. in a laboratory, the speaker being taken out of his natural context to produce speech samples for an experimental study. Se elicitaron las palabras en el contexto de oraciones o preguntas para que los hablantes contestaran directamente con la palabra que se esperaba. Las preguntas trataron de ser interesantes, amenas, o al menos indicaban algo más que solamente, ¿qué es esto? o ¿cómo se le llama a esto?

\section{Resultados}

Los resultados obtenidos en la encuesta realizada se presentan a continuación. Si bien es cierto algunos de los autores presentados anteriormente no creen en la diferenciación que hay en español entre semiconsonantes y semivocales, algunos casos encontrados (o muchos casos en el dominio hispánico) de consonantización o cuasi consonantización de las deslizadas en posición inicial de sílaba o de palabra suponen que sí hay una distinción fonética entre las deslizadas en diptongos crecientes y en decrecientes, sobre todo cuando en los casos de diptongos crecientes las deslizadas pueden llegar a tener algún tipo de constricción, como lo muestran algunas consonantizaciones presentadas más abajo y confirmadas para muchos dialectos del español. Este reforzamiento, sin embargo, no es posible en posición decreciente; antes bien, en los datos se nota, en esta posición, un debilitamiento tendiente al acortamiento y debilitamiento de la deslizada. 
Los resultados de la investigación en términos cuantitativos son los siguientes:

\section{a) Diptongos en posición inicial de palabra}

Cuadro 8. Diptongos en posición inicial de palabra

\begin{tabular}{|c|c|c|}
\hline Palabra en posición inicial & Con consonantización & Sin consonantización \\
\hline huevo & $\begin{array}{l}\text { [gweßo]: } 14,28 \% \\
\text { [ұweßo]: } 14,28 \%\end{array}$ & [weßo]: 71,42\% \\
\hline huecos & $\begin{array}{l}\text { [gwekos]: } 28,57 \% \\
\text { ['ywekos]: } 28,57 \% \\
\text { ['bwekos]: } 14,28 \%\end{array}$ & [wekos]: $42,85 \%$ \\
\hline huesos & ['gwesos]: $14,28 \%$ & ['wesos]: $85,72 \%$ \\
\hline hierro & $0 \%$ & ['jero]: $100 \%$ \\
\hline hielo & $0 \%$ & ['jelo]: $100 \%$ \\
\hline hierba & $0 \%$ & ['jerba]: $100 \%$ \\
\hline
\end{tabular}

Este grupo de palabras presenta resultados interesantes en el sentido de que los diptongos iniciales con ie se dan en un $100 \%$ sin ningún tipo de consonantización al inicio de la palabra. Esto apoya la propuesta de la investigadora en el sentido de que, efectivamente, se dan diptongos en posición inicial, con sus variantes semiconsonánticas adscritas al fonema vocálico /i/. Al preguntarle a una persona cualquiera que si le parecía que yerba 'hierba' o yelo 'hielo' sonaban bien, contestó que esa era una pronunciación incorrecta.

Por otro lado, los diptongos iniciales con ue fueron un poco más susceptibles de consonantización, aunque no en la cantidad en que los autores anteriores señalan para esta posición (fueron entre 14,28\% y 28,57\%). Recordando a D'Introno (1995), la condición para que la deslizada se consonantice, es que esta aparezca a inicio de sílaba. Tal condición es necesaria puesto que el ataque es un constituyente constante de la sílaba, al igual que el núcleo vocálico, y a nivel fonológico contiene una consonante. La sílaba por excelencia sería, entonces, constituida por CV. Por tanto, la deslizada es originalmente una vocal que resilabea cuando una sílaba tiene un ataque vacío, lo cual hace que dicha vocal se convierta en un ataque -vocálico.

La investigadora, a la luz de los datos, supone que la interpretación fonológica más adecuada sigue siendo la tradicional, propuesta por Navarro Tomás la cual propone que existen diptongos en posición inicial absoluta y que estos se representan por los fonemas /i/ /u/ y la vocal -alta del núcleo. En la pronunciación de los diptongos iniciales ie, se ha observado, en un $100 \%$ de los casos, la realización fonética de [j] aproximante o semiconsonántica, sin ningún tipo de obstrucción o consonantización.

Por otra parte, y dado que hay cierto porcentaje de consonantización delante de los diptongos iniciados en $u e, \mathrm{y}$ aunque no se comparte la interpretación fonológica de Alarcos Llorach respecto de su secuencia de fonemas /gu/ en posición inicial de palabra (difonemática), 
sí se comparte su propuesta de un refuerzo consonántico solo para [w], [gw] o [yw], en posición inicial de palabra, lo cual se corrobora en la investigación con un rango de reforzamiento del 14,28\% al 28,57\%, el cual no es despreciable. Por su parte, Cressey (1978:29) señala, también, una $\left[\mathrm{\gamma}^{\mathrm{w}}\right]$, es decir, una fricativa velar labializada, con los rasgos [+alto, +posterior, +redondeado]. Además, es válido repasar la cita de D’Introno y otros (1995: 235), quienes señalan:

\begin{abstract}
Un proceso que revela la existencia de un constituyente prenuclear, porque afecta a este constituyente independientemente de la vocal, es el de la consonantización de una deslizada prenuclear. Por ejemplo la palabra "huevo" se pronuncia en algunos dialectos con una velar inicial, por consonantización de la deslizada [w]: [gw]evo. Ahora bien, este proceso afecta al "constituyente" prenuclear porque, como veremos más tarde, el tipo de consonantización depende del tipo de la deslizada presente. En otros términos la deslizada da origen a una consonante que comparte ciertas características con la deslizada, de modo que ambos, deslizada y consonante, forman parte de un constituyente prenuclear.
\end{abstract}

Los resultados también respaldan la propuesta de la investigadora de que el núcleo vocálico, en estos casos, no corresponde a un núcleo complejo, sino que la vocal [-alta] corresponde al núcleo vocálico de la sílaba y la deslizada al margen silábico puesto que, en los casos ya señalados, la pronunciación presentó claramente un elemento consonántico como ataque de la sílaba inicial. Por supuesto, en su mayoría se presentan realizaciones semiconsonánticas de /u/ sin consonantización previa (42,85\%, 71,42\% y 85,72\%), es decir, conforman una sílaba con ataque -consonántico -vocálico y un núcleo +vocálico.

\title{
b) Diptongos crecientes y decrecientes
}

Cuadro 9. Frecuencias de diptongos crecientes y decrecientes

\begin{tabular}{|c|c|c|}
\hline $\begin{array}{l}\text { Palabras con diptongos } \\
\text { crecientes y decrecientes }\end{array}$ & $\begin{array}{l}\text { Concurrencia de vocales } \\
\text { en una sola sílaba }\end{array}$ & $\begin{array}{l}\text { Concurrencia de vocales } \\
\text { en sílabas separadas }\end{array}$ \\
\hline diente/muela & ['djen.te]: $100 \%$ & $0 \%$ \\
\hline diablo & ['dja.ßlo]: $100 \%$ & $0 \%$ \\
\hline puerto & ['pwer.to]: $100 \%$ & $0 \%$ \\
\hline guaria & ['gwa.rja]: $100 \%$ & $0 \%$ \\
\hline \multirow[t]{2}{*}{ lluvia / lloviendo } & ['dzu.ßja]:100\% & $0 \%$ \\
\hline & [dzo.'ßjen.do]:100\% & $0 \%$ \\
\hline baila & [bai.'lar]: $100 \%$ & $0 \%$ \\
\hline maullar & [maun.'jar]: $100 \%$ & $0 \%$ \\
\hline
\end{tabular}

Los diptongos crecientes y decrecientes presentan, en su totalidad, la concurrencia de vocales en una sola sílaba, sin variaciones. Sin embargo, se deben investigar con mayor 
profundidad diferentes estilos y quizás situaciones en una muestra estratificada, pues no pareciera que, por estos datos, hubiera frecuencia alguna de separación silábica de las vocales que conforman los diptongos.

En estos casos, la semiconsonante sería parte de la posición prenuclear y las semivocales, que no se consonantizan en dicha posición, formarían parte de la posición posnuclear. Así se resuelve el problema de ubicar fonológicamente vocales simples y complejas como lo hace, por ejemplo, Navarro Tomás (1946), quien propone para el español cuarenta y dos fonemas; cinco vocales, diecinueve consonantes, seis diptongos decrecientes, ocho crecientes y cuatro triptongos, o como lo hacen Bowen \& Stockwell (1955) y corrobora Saporta (1956), quienes propondrían 13 fonemas silábicos (5 vocales y 8 diptongos, incluyendo el que añade Saporta, /ow/).

c) Concurrencia de vocales en sílabas distintas: el hiato

Cuadro 10. Frecuencias de aparición de hiatos

\begin{tabular}{lcc}
\hline Palabras con hiato & $\begin{array}{c}\text { Concurrencia de vocales } \\
\text { en una sola sílaba }\end{array}$ & $\begin{array}{c}\text { Concurrencia de vocales } \\
\text { en sílabas separadas }\end{array}$ \\
\hline leopardo & [leo.'pardo]: $85,72 \%$ & [le.o.'pardo]: $14,28 \%$ \\
vía láctea & [,bi.a.'lak.tea]: $57,15 \%$ & [bi.a.'lak.te.a]: $42,85 \%$ \\
\hline
\end{tabular}

En los manuales de dialectología se ha señalado la tendencia general del español de América a la diptongación de los hiatos (sinéresis). Sin embargo, en una muestra tan pequeña como la estudiada, se han observado algunos casos de concurrencia de vocales en sílabas distintas que, si bien no marcan una tendencia, sí representan cierto porcentaje de separación de núcleos silábicos que forman hiatos (14,28\% y 42,85\% para leopardo y láctea, respectivamente). Una muestra representativa y estratificada podría dar luz acerca de esta pronunciación en diferentes estilos de habla. Aun cuando se supone que un diptongo se forma por una vocal alta más otra vocal -alta que constituye el núcleo silábico, lo más relevante en la conformación de un diptongo es, en realidad, la confluencia de vocales articuladas en una sola sílaba, sin que sea tan relevante la cualidad vocálica.

\section{Conclusiones}

El estudio de las deslizadas en español ha mostrado las divergencias existentes en su interpretación fonológica.

Existen posiciones diversas respecto del estatus fonológico de las deslizadas, y sobre la posición que ocupan en la sílaba.

Este trabajo explora la posibilidad estudiada y analizada con anterioridad a) de que su estatus fonológico sea que se produzcan fonéticamente a partir de los fonemas vocálicos altos /i/, /u/, b) de que estos segmentos no formen parte en núcleos de sílaba complejos, y c) de que posean características fonéticas diferentes dependiendo de si aparecen en diptongos 
ascendentes o descendentes.

A lo largo de la exploración fonética por medio de una encuesta lingüística realizada a siete hablantes adultos del español, se ha llegado a las siguientes conclusiones:

1. Existen diptongos en posición inicial de palabra y estos se representan por los fonemas /i/ /u/, con realizaciones semiconsonánticas. Dado que hay cierto porcentaje de consonantización delante de los diptongos iniciados en $u e$, se propone un refuerzo consonántico solo para [w]: [gw] o [yw], de ataque, en posición inicial de palabra, lo cual se corrobora en la investigación con un rango de reforzamiento del 14,28\% al 28,57\%.

2. Los resultados también respaldan la propuesta de la investigadora de que el núcleo vocálico, en estos casos, no corresponde a un núcleo complejo, sino que la vocal [-alta] corresponde al núcleo vocálico de la sílaba y la deslizada a la coda o margen silábico, puesto que, en los casos ya señalados, la pronunciación presentó claramente un elemento consonántico como ataque de la sílaba inicial. Los diptongos crecientes y decrecientes presentan, en su totalidad, la concurrencia de vocales en una sola sílaba, sin variaciones. En estos casos, la semiconsonante es parte de la posición de ataque y las semivocales, que no se consonantizan en dicha posición, forma parte de la coda. Así se resuelve el complejo problema de la representación fonológica de un sistema de vocales simples y complejas.

3. Algunos casos encontrados en esta investigación (y quizás muchos en el dominio hispánico) de consonantización o cuasi consonantización de las deslizadas en posición inicial de sílaba o de palabra suponen que sí hay una distinción fonética entre las deslizadas en diptongos crecientes y las que se dan en diptongos decrecientes, sobre todo cuando en los casos de diptongos crecientes las deslizadas pueden llegar a tener algún tipo de constricción, como lo muestran algunas consonantizaciones presentadas más abajo y confirmadas para muchos dialectos del español. Este reforzamiento, sin embargo, no es posible en posición decreciente; antes bien, en los datos se nota, en esta posición, un debilitamiento tendiente al acortamiento y debilitamiento de la deslizada.

4. Adicionalmente, ha llamado la atención que en los manuales de dialectología se señale la tendencia general del español de América a la diptongación de los hiatos (sinéresis). Sin embargo, en una muestra tan pequeña como la estudiada, se han observado algunos casos de concurrencia de vocales en sílabas distintas que, si bien no marcan una tendencia, representan cierto porcentaje de separación de núcleos silábicos como corresponde a los hiatos.

5. Se recomienda una investigación más profunda sobre el tema, con el fin de ratificar las propuestas que en este estudio se han esbozado. Aún queda mucho por hacer respecto del tema de la diptongación en español.

\section{Notas}

1. Siguiendo a Calvo Shadid (1990:76), se señalan algunos argumentos proporcionados desde hace algunas décadas en favor del llamado desdoblamiento vocálico, que haría pasar de un sistema de cinco a uno de siete vocales en algunos dialectos del español que aspiran o eliden /s/ final de sílaba morfemática; al elidirse, por ejemplo, la /s/ de plural, en estos dialectos se lleva a cabo la apertura de la vocal final o la de todas las vocales en la palabra. Estudios como el de Navarro (1939) para el español andaluz peninsular, Hooper (1976) para el español de Andalucía, particularmente para Andalucía Oriental (se basa en Alonso et al (1950)), Vázquez (1953) para Uruguay, Matluck (1961) para Puerto Rico, Honsa (1965) para Argentina, Haden y Matluck (1973) para Cuba, entre otros, tratan de demostrar que este rasgo permite establecer diferencias semánticas significativas al convertirse dicha apertura vocálica en el marcador 
del plural nominal. Sin embargo, otros estudios posteriores han demostrado la imposibilidad de sostener el argumento del desdoblamiento vocálico al elidirse la /s/ morfemática: Clegg (1967) para Cuba, Cedergren (1973 y 1978) para Panamá, Hammond (1976) para el español cubano de Miami, Alemán (1977) para Puerto Rico, Terrel (1977a) para Cuba y Puerto Rico, Poplack (1980) para Puerto Rico, Alba (1982) para Santiago de los Caballeros, Hundley (1987) para Perú. Para Terrel (1977b) y López Morales (1971, 1983), la regla de elisión de /s/ desempeña un papel importante en la gramática: si la marca es redundante hay mayor elisión; esto es, la regla de elisión apunta a la simplificación de la redundancia en las estructuras léxicas. Posteriormente, Hualde (1994) y Galindo (1997) señalan para el andaluz oriental, que /s/ subyacente bloquea un proceso de sinalefa que opera en singular [laen.'tra] 'la entrada' frente a una diferencia en la silabificación en el plural, [la.en.'tra]. (Cf. Núñez-Cedeño y Morales Front (1999).

2. Estable se refiere aquí al sentido que le da Mosterín (1981:101), pues no es un sistema que haya perdido oposiciones vocálicas, como sí lo han hecho el francés y el italiano, por ejemplo.

3. Cf. Alarcos (1961/83:150).

4. Con excepción de /e/ y /o/ al formar transiciones del tipo sinéresis en algunos hiatos: 'aéreo': a.é.reo; 'cohete': coe.te, por ejemplo, y quizás de /a/ al acortarse en casos como 'maestría': maes.trí.a, o 'ahorita': ao.ri.ta, en que formaría también una transición junto a otra vocal inacentuada.

5. El autor utiliza los símbolos gy b, respectivamente.

6. Los autores utilizan el símbolo [y]

7. S corresponde a una semivocal o semiconsonante

8. $\quad$ R corresponde a una líquida, , o l en español.

9. La autora utiliza el símbolo [y].

10. La autora utiliza el símbolo [y̌].

11. Según Alarcos (1950/83:151-152), la primera de esas reglas es que tales sonidos, en ciertas circunstancias, no formen parte de dos sílabas distintas sólo es cumplida por los ocho diptongos crecientes y por [au], [eu] y [ou ].Los tres diptongos [ai], [ei] y [oi], quedan desprovistos de valor monofonemático, ya que, cuando van seguidos de vocal en la cadena hablada, sus elementos pueden repartirse entre sílabas sucesivas: ay, pero a-yes; rey, pero re-yes; hoy, pero hoyes tarde [o-yes-tár-de]. Además, si un fonema vocálico se pone en contacto con otra vocal en el decurso, su reunión se realiza con frecuencia como diptongo (...). Según la regla sexta de Trubetzkoy (...), una combinación de sonidos potencialmente monofonemática sólo debe valorarse como fonema único cuando uno de aquellos sonidos no pueda considerarse variante combinatoria de ningún otro fonema. Es claro que los componentes (...) de los diptongos españoles son realizaciones diversas de los fonemas vocálicos (...). Por tanto, los diptongos carecen de valor monofonemático y son combinaciones de los cinco fonemas vocales con otro elemento.

12. Probablemente el autor se refiera, con este símbolo, a una fricativa palatal del tipo [ j ].

13. Como lo plantean Bowen \& Stockwell (1955).

14. El autor utiliza el símbolo [ y̌]. 
15. Respecto del plural en estos casos, señala (1961/83:156): En el nivel morfológico puede argüirse que en rey, ay, ley, etc., tenemos el fonema /y/, porque en el plural se añade el significante -es, típico de aquellos signos cuyo singular acaba en consonante (miel-mieles, red-redes, luz-luces, etc.); pero si se añade -es a rey, etc., es porque son monosílabos o, como en el caso de bocoy-bocoyes, porque son oxítonos, y todo singular oxítono acabado en vocal también agrega -es: albalá-albaláes, los síes, las aes, baladíes, sefardíes, etc. (Cuando, en la Edad Media, se decía maravedís, también se decía reys, bueys, etc.). La objeción no es, pues, válida.

16. Se ha cambiado la representación de la oclusiva /g/ de Alarcos por la del AFI /g/.

17. El autor usa los símbolos [ j] y [̌̌ $]$.

18. De acuerdo con su propuesta debería ser, sin embargo, adiero, pues el autor adscribe la [ $\mathrm{j}$ ] del diptongo creciente al fonema /i/ y al grafema i.

19. Señalan otras como viaje, dieta, cruel, embrión, fastuoso, que parecen producirse también con ambas realizaciones.

20. Los autores usan, para este caso, el símbolo [y].

21. La estructura moraica tiene que ver con el peso silábico y hace referencia a la rima silábica.

22. Esta explicación se basa en lo anotado por Núñez Cedeño y Morales Front (1999).

\section{Bibliografía}

Aguilar, L. y M. Machuca. 1995. "Pragmatic factors affecting the phonetic properties of diphthongs". En: Pardo, J.M. Enríquez, E. Ortega, J.- Ferreiros, J.- Macías, J.Valverde, F.J. (eds.) Eurospeech '95 Proceedings of the 4th ${ }^{\circ}$ European Conference on Speech Communication and Technology. Madrid: 18-21 de septiembre de 1995. Vol 3, 2251-2254.

Alarcos Llorach, E. 1961/83. Fonología española. Madrid: Editorial Gredos.

Alba, O. 1982. "Estratificación social del español de Santiago: Variación de la /s/ implosiva". Tesis de maestría: Universidad de Puerto Rico.

Alemán, I. 1977. "S final de sílaba implosiva y de final de palabra en el español de Puerto Rico". Tesina: Universidad de Puerto Rico.

Alonso, D. et al. (1950). "Vocales andaluzas. Contribución al estudio de la fonología peninsular". Nueva Revista de Filología Hispánica. 4: 209-30.

Boden, J. D. \& R. P. Stockwell 1955. “The phonemic Interpretation of Semivowels in Spanish”. Language. 31: 236-240. 
Calvo Shadid, A. 1990. "El plural en los sustantivos terminados en vocal en el cantón de Curridabat: estudio cuantitativo". Revista de Filología y Lingüística de la Universidad de Costa Rica. 16 (2): 75-83.

Catalán, D. 1964-65. "Nuevos enfoques de la fonología española”. Romance Philology. 18: 178-91.

Cedergren, H. 1973. "The interplay of social and linguistic factors in Panama". Tesis doctoral: Universidad de Cornell.

Clegg, H. 1967. "Un análisis acústico de las vocales cubanas”. Tesis doctoral: Universidad de Texas.

1978. "En torno a la variación de s final en Panamá: análisis cuantitativo".

Delforge, A. M. 2008. Unstressed Vowel Reduction in Andean Spanish. In Selected Proceedings of the 3rd Conference on Laboratory Approaches to Spanish Phonology, ed. Laura Colantoni and Jeffrey Steele, 107-124. Somerville, MA: Cascadilla Proceedings Project.

Galindo, M. Á. 1997. "A study on Eastern Andalusian Dialectology: A Phonemic Description of the Syllable-final Consonant System of the Dialect Spoken in Montejícar (Granada)". Tesis doctoral inédita. University of Illinois at Urbana-Champaign.

Hualde, J. 1991. “On Spanish Syllabification”. En: Campos, H. y F. Martínez-Gil (eds.) Current Study in Spanish Linguistics.Washington DC: Georgetown University Press, 475-493.

1994. "La contracción silábica en español”. En: Gramática del español: 629-647. V. Demonte, ed. México: El Colegio de México (Publicaciones de la Revista de Filología Hispánica, VI).

Hundley, J. 1983. "Linguistic Variation in Peruvian Spanish: Unstressed vowel and /s/". Tesis doctoral: Universidad de Minesota.

Haden, E.F. y J.H. MatIuck. 1973. "El habla culta de La Habana: Análisis fonológico preliminar". Anuario de Letras. 11: 5-33.

Hammond, R. 1976. "Phonemic restrueturing of voiced obstruents in Miami - Cuban Spanish". Aid et al. (eds.) Colloquium Of Hispanic Linguistics. Washington: Georgetown University Press, 42-5.

Harris, J.W. 1983. Syllable Structure and Stress in Spanish: a Nonlinear Analysis. Cambridge, MA: The MIT Press.

Honsa, V. 1965. “The Phonemic Systemnis of Argentinian Spanish”. Hispania. 48: 275-83. 
Hooper, J. 1976. An Introduction to Natural Generative Phonology. New York: Academic Press, Inc. http://liceu.uab.es/ joaquim/publicacions/SpeakingStyles_92.pdf

Llisterri, J. (1992) "Speaking styles in speech research". In: Workshop on Integrating Speech and Natural Language. Dublin, Ireland, 15-17 July 1992.

Lope Blanch, J. (ed). 1977. Estudios sobre el español hablado en las principales ciudades de América. México: Universidad Autónoma de México.

López Morales, H. 1971. Estudios sobre el español de Cuba. Nueva York: Las Américas Publishing Co.

1978. Corrientes actuales de la dialectología del Caribe Hispánico. Río Piedras: Editorial Universitaria.

1983. Estratificación social del español de San Juan de Puerto Rico. México: Universidad Autónoma de México.

Macpherson, I. R. 1975. Spanish Phonology: Descriptive and Historical. Manchester University Press.

Matluck, J. 1961. "Fonemas finales en el consonantismo puertorriqueño". Nueva Revista de Filología Hispánica. 15: 332-42.

Mosterín, J. 1981. La ortografía fonémica del español. Madrid: Alianza Editorial, S.A.

Navarro Tomás, T. 1918/61. Manual de pronunciación española. Madrid: Consejo Superior de Investigaciones Científicas.

1946/66. Estudios de fonología española. New Cork: Las Americas Publishing Company.

Núñez Cedeño R.A. y Morales-Front A. 1999. Fonología generativa contemporánea de la lengua española. Washington DC: Georgetown University Press.

Poplack, S. 1980. “Deletion and desambiguation in Puerto Rican Spanish”. Language. 56: 37185.

Terrel, T. 1977a. "Constraints on the Aspiration and Deletion of Final /s/ in Cuban and Puerto Rican Spanish". Bilingual Review. 4: 35-51.

1977b. "La aspiración y elisión en el español cubano: implicaciones para una teoría fonológica dialectal". Lope Blanch (ed.). Trubetzkoy, N. 1939. Grundzüge der Phonologie. Praga.

Vázquez, W. 1953. "El fonema s en el español de Uruguay". Revista de la Facultad de Humanidades y Ciencias. 10: 87-94. 